\title{
Research and Application of Directional Roof Cutting and Pressure Releasing Technology for Retracement Channel of 3314 Working Face in Hexi Coal Mine
}

Jindong Cao ( $\square$ caojindong2019@163.com )

China University of Mining and Technology State Key Laboratory for Geomechanics and Deep

Underground Engineering

\section{Xiaojie Yang}

China University of Mining and Technology - Beijing Campus

\section{Ruifeng Huang}

China University of Mining and Technology - Beijing Campus

\section{Qiang Fu}

China University of Mining and Technology - Beijing Campus

\section{Yubing Gao}

China University of Mining and Technology - Beijing Campus

\section{Research Article}

Keywords: Surrounding rock control, Retracement channel, Roof cutting and pressure releasing, Key parameters

Posted Date: May 18th, 2021

DOl: https://doi.org/10.21203/rs.3.rs-449704/v1

License: (c) (i) This work is licensed under a Creative Commons Attribution 4.0 International License. Read Full License 


\title{
Research and Application of Directional Roof Cutting and Pressure Releasing Technology for Retracement Channel of 3314 Working Face in Hexi Coal Mine
}

\author{
Jindong $\mathrm{CaO}^{1,2}$, Xiaojie Yang ${ }^{1,2}$, Ruifeng Huang ${ }^{1,2}$, Qiang $\mathrm{Fu}^{1,2}$, Yubing Gao ${ }^{1,2}$ \\ 1 State Key Laboratory of Geomechanics \& Deep Underground Engineering, China University of Mining \& \\ Technology, Beijing 100083, China; \\ 2 School of Mechanics and Civil Engineering, China University of Mining \& Technology, Beijing 100083, China
}

\begin{abstract}
:
The high stress of the surrounding rock of Hexi Coal Mine easily leads to severe deformation of the retracement channel and the appearance of the mine pressure during the retreat severely affects the stability of the roadway. In order to solve the above problems, a roadway surrounding rock control technology is proposed and tested. The bidirectional energy-concentrated tensile blasting technology is used to perform directional cutting to cut off the stress propagation path. Firstly, the deformation mechanism of the roof is analyzed by establishing the deformation mechanical model of the roof of the retracement channel. Then, according to the geological conditions of working face 3314 and theoretical calculation, the key parameters of roof cutting and pressure releasing of retracement channel are determined, and through the numerical analysis of its cutting effect, the length of cutting seam is $11.5 \mathrm{~m}$, and the cutting angle is $10^{\circ}$. Finally, a field test is carried out on the retracement channel of 3314 working face to verify the effect of roof cutting. The results show that the deformation of the retracement channel and the main roadway is very small. In the process of connecting the working face and the retracement channel, the maximum roof to floor convergence is $141 \mathrm{~mm}$, and the two sides convergence is $79 \mathrm{~mm}$. After the hydraulic support was retracted, the maximum roof to floor convergence of the surrounding rock is $37 \mathrm{~mm}$, and the two sides convergence is $33 \mathrm{~mm}$. The roof cutting and pressure releasing of the retracement channel ensures the safe evacuation of the equipment and the stability of the main roadway. The cutting effect is obvious for the release of pressure, which is of great significance to engineering practice.
\end{abstract}

Key words: Surrounding rock control, Retracement channel, Roof cutting and pressure releasing, Key parameters

\section{Introduction}

The coal resource plays an important role as an important energy resource in the world. At present, the efficient mining of coal resources is an important challenge facing the world coal industry (Peng H et al. 2019; Ma JM et al. 2016; Yuan Y et al. 2013). The retracement work in coal mining is 
of great significance for speeding up coal mining (Zhang GD et al.2012; Varden R et al. 2008). The retracement technology is mainly divided into pre-excavation retraction channels and non-preexcitation retraction channels. Pre-excavating the retracement channel can greatly improve the speed of safe and smooth evacuation of related equipment. The mine pressure of the working face appears violent under the influence of the advance pressure When the working face is more and more close to the retracement channel (Liqing D et al.2013; Wang C et al.2018). The surrounding rock deformation of the retracement channel is serious, which seriously restricts the retracement speed (Gong P et al. 2018).

A large number of scholars have carried out research in view of the above problems. The mechanism of the problems such as slope and floor heave in the retracement channel of heavy fully mechanized mining face, and put forward a rapid retracement technology of long-distance multi Lane in deep heavy-duty fully mechanized face (Shu CX, Jiang FX, Han Y et al (2018). The relationship between the roof fracture location and the stress of the protective pillars of the retracting channel after penetration, and established the roof structure model of the retracting channel based on the theory of elastic mechanics (Gu SC, Huang RB, Li, JH et al (2017). The deformation and failure of the surrounding rock of the retreat channel were mainly caused by the mining face and periodic pressure through the theoretical analysis and numerical simulation of the mine pressure law at the end of the working face (Wang G 2017). Wang GJ et al. applied UDEC to compare the scaffolding support scheme with the anchor-mesh-cable combined support scheme. The results show that the anchormesh-cable combined support has a good effect and can carry out the retracement work safely and efficiently (Wang GJ et al.2013). Fei L et al. studied the deformation rules, surrounding rock stress distribution characteristics and failure mechanism of the retracement channel by using the methods of theoretical analysis, numerical calculation and field industrial test (Fei L et al.2018). The optimization of multi-channel retracement technology can effectively control the surrounding rock deformation of the retracement channel (Li YS et al.2010).

He MC put forward the technology of gob-side entry retaining, which has been successfully applied in many mines. (He MC et al. 2015; He MC et al. 2017; Wang Q et al. 2018). The purpose of optimizing the stress distribution is achieved by changing the surrounding rock structure of the roadway and cutting off the stress transfer of the roof. (Zhang Y et al. 2019; Qiang X et al. 2019) The roof can collapse according to the designed position, making the roadway in the pressure releasing area and reducing the threat of high stress environment after roof cutting (Chen Y et al. 2019; He MC et al.2019; Sun XM et al. 2014). This paper makes a roof-cutting study on the withdrawal channel of 3314 working face in Hexi Coal Mine Based on the above research. 


\section{Project General Situation}

The Hexi coal mine is located in Liulin County, Shanxi Province, China. The mine field is an irregular polygon, slightly square, $6.170 \mathrm{~km}$ long from east to west, $5.635 \mathrm{~km}$ wide from south to north, and $18.908 \mathrm{~km}^{2}$ in area, as shown in Fig. 1.

The immediate roof of the 3314 working face is mudstone, $5.39 \mathrm{~m}$ thick. The basic top is sandy mudstone, $9.70 \mathrm{~m}$ thick. The direct bottom is fine mudstone, $9.14 \mathrm{~m}$ thick. The old bottom is sandstone. The 3314 working face is mining 3 \# coal seam of Shanxi Group. The strike length of the working face is $2200 \mathrm{~m}$, and the inclined length is $170 \mathrm{~m}$. It is low ash and low sulfur main coking coal. According to the drilling data and downhole measured data, the geological structure is relatively simple, showing monoclinic structure and secondary fold structure, inclining to SW. The thickness of coal seam is $1.13 \sim 2.37 \mathrm{~m}$, with an average of $1.75 \mathrm{~m}$, and the bulk density $1.39 \mathrm{t} / \mathrm{m}^{3}$. The elevation of coal seam floor in working face is $+607.7 \sim+685.6 \mathrm{~m}$. The retracement channel is $2.4 \mathrm{~m}$ high and $5.0 \mathrm{~m}$ wide. The histogram of coal seam and top and bottom rock strata is shown in Fig. 2. The layout of 3314 working face and roadway is shown in Fig. 3.

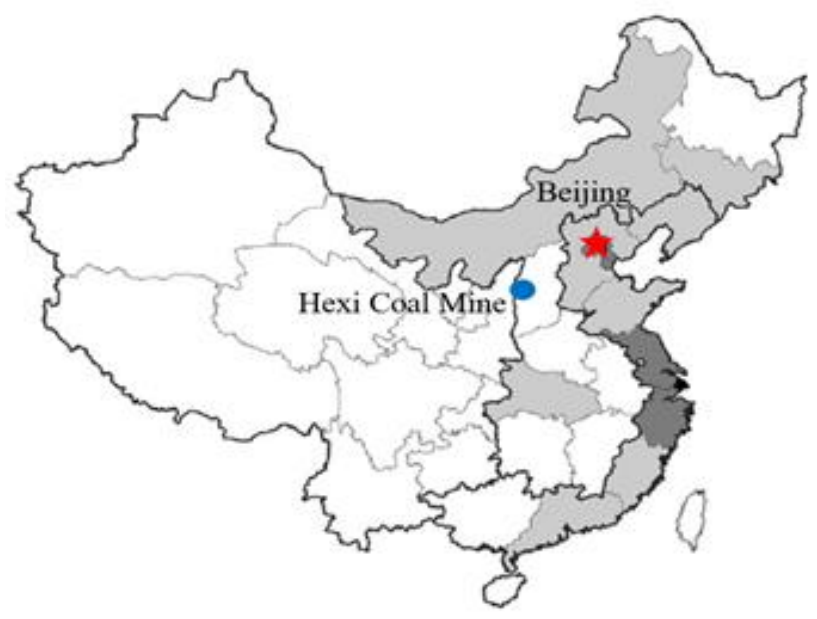

Fig.1 The location of the Hexi coal mine 


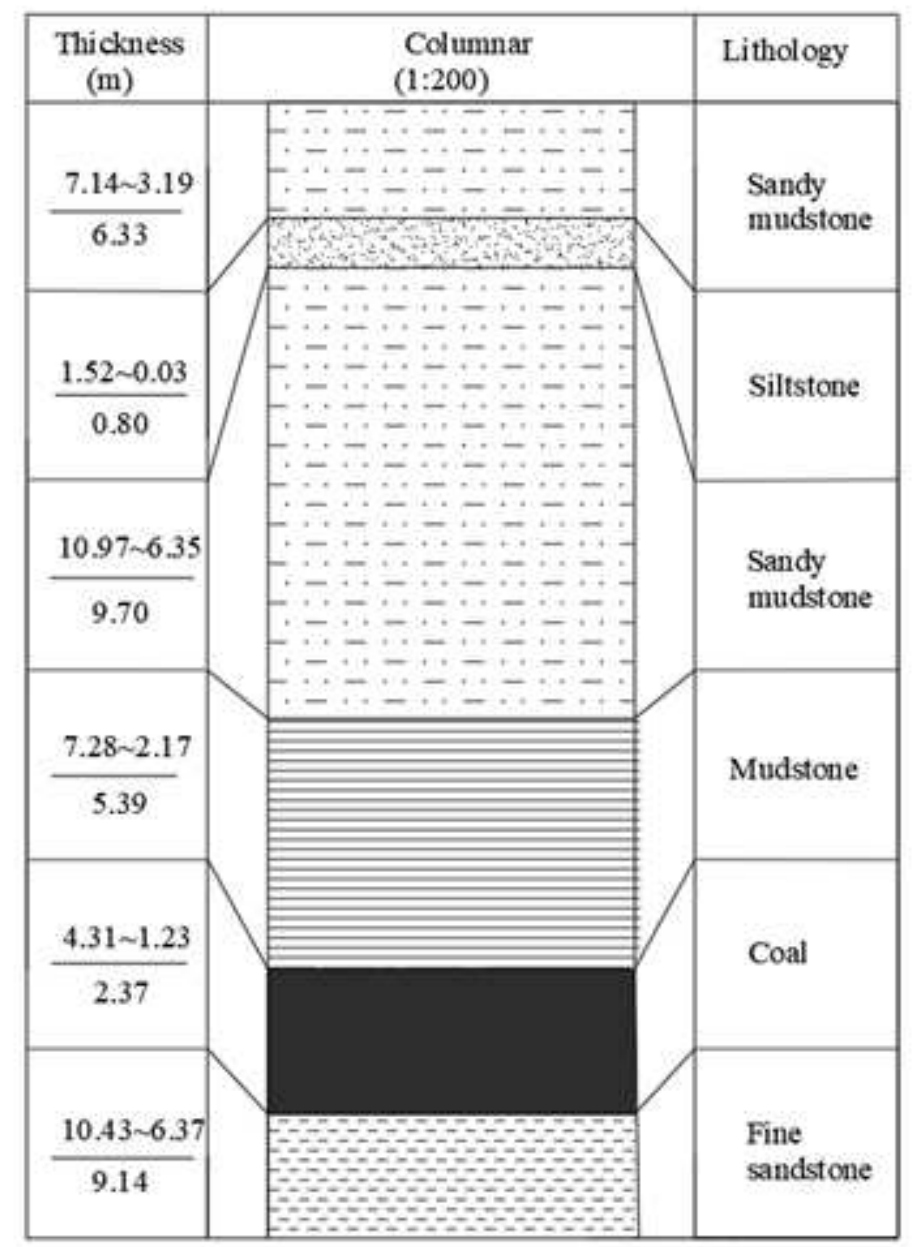

Fig.2 Stratigraphic histogram

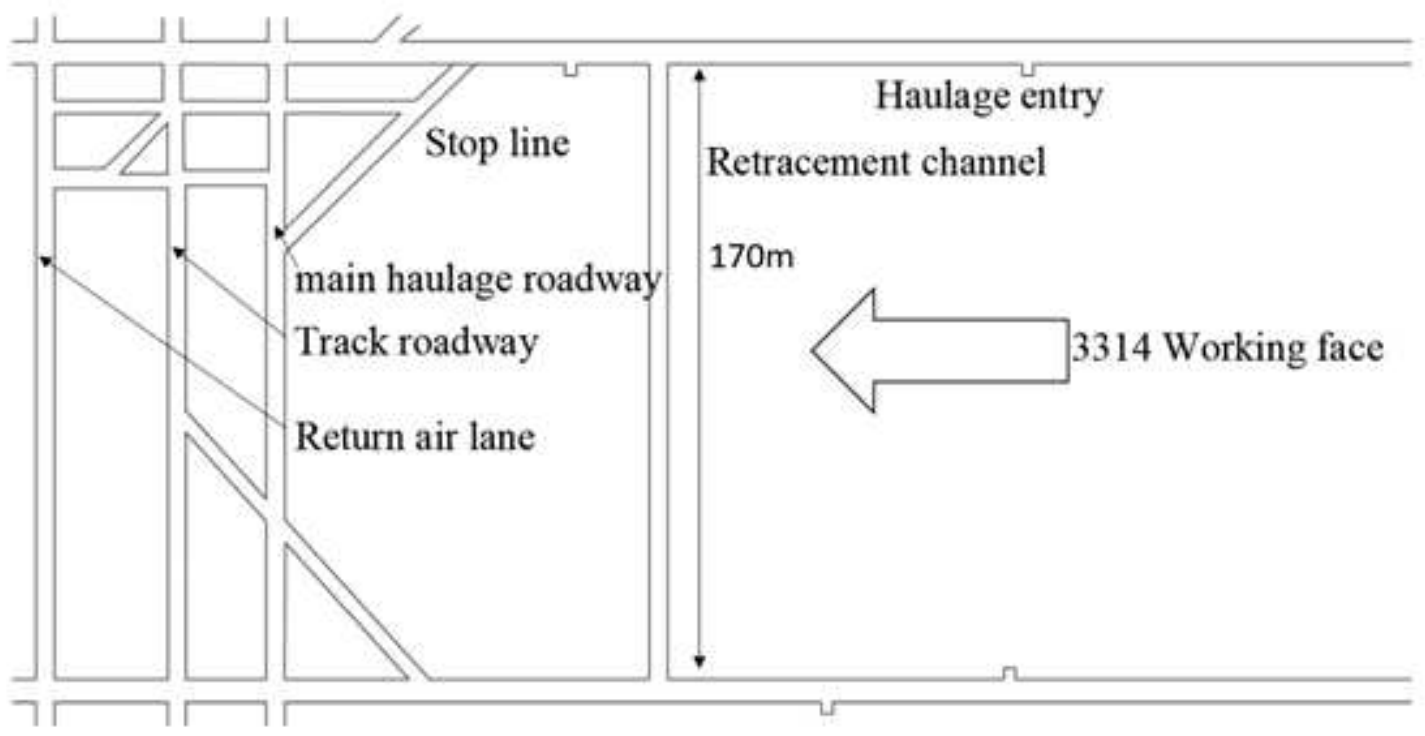

Fig.3 The layout of 3314 working face and roadway

\section{The technology of directional roof cutting and pressure releasing}

The technology of directional roof cutting and pressure releasing is mainly to achieve directional seam cutting through the concentrated energy blasting device. The stress on the solid coal side will 
be greatly reduced by cutting the roof above the side of the goaf, which will reduce the deformation of the roadway. The key parameters of roof cutting are optimized and analyzed, so that the cut roof can fill the goaf well and play a supporting role according to the expansion characteristics of rock. 3.1 Analysis on roof structure of retracement tunnel

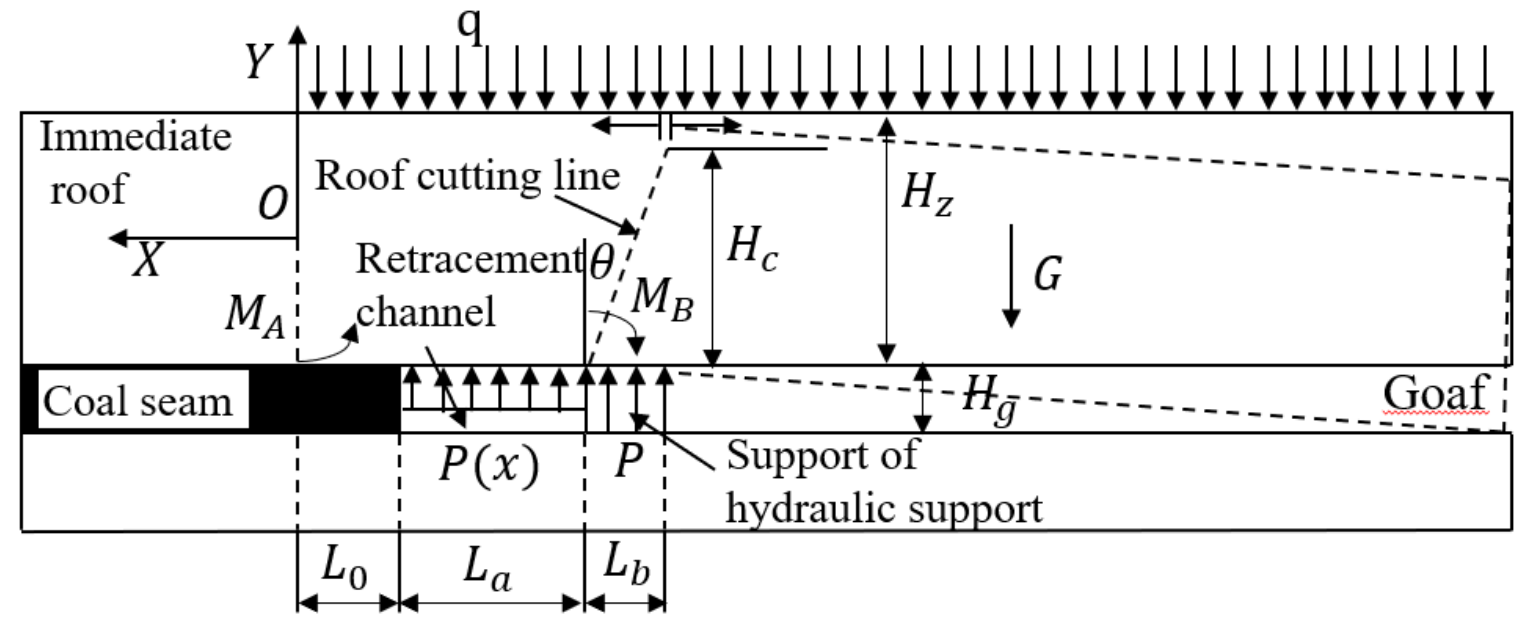

Figure 4 Mechanical model of retracement channel roof

The main purpose of retracement channel is to remove the relevant equipment of working face. The stability of the surrounding rock determines whether the working face equipment can be removed smoothly, and also affects the stability of the main roadway to a certain extent.

According to the movement law of the overlying roof rock layer, the roof undergoes the initial pressure and periodic pressure, and the direct roof will rotate and deform, forming a "cantilever beam" structure in the process of mining. The mechanical model of retracement channel roof is established as shown in Fig. 4. Where $q$ is the uniform load acting on the roof; $M_{A}$ is the residual bending moment of rock beam at $\mathrm{A} ; M_{B}$ is the residual bending moment of rock beam at $\mathrm{B} ; L_{0}$ is the width of the stress limit equilibrium zone in the coal; $L_{a}$ is the width of the retracement channel; $L_{b}$ is the width of the hydraulic support; $H_{c}$ is the height of pre-split cutting roof; $H_{g}$ is the height of the goaf; $\mathrm{G}$ is the gravity produced by the self-weight of the direct roof; $P_{a}$ is support load in the roadway; $P$ is the support resistance of the hydraulic support.

The hydraulic support to ensure the stability of the retracement tunnel is in the stress concentration area. The hydraulic support bears a huge roof pressure, which is easy to cause pressure and is not conducive to retracement. The roof structure can be regarded as a "long-arm beam" when the roof is not cut. The pressure of the roof rock layer is very large, which seriously affects the stability of the retraction channel and requires a large support resistance. The roof structure can be regarded as a "short-arm beam" when the roof is cut at a predetermined position. The pressure on the roof rock layer will be greatly reduced. The idea of roof cutting and pressure releasing is to transform the "longarm beam" structure into the "short-arm beam" structure. 


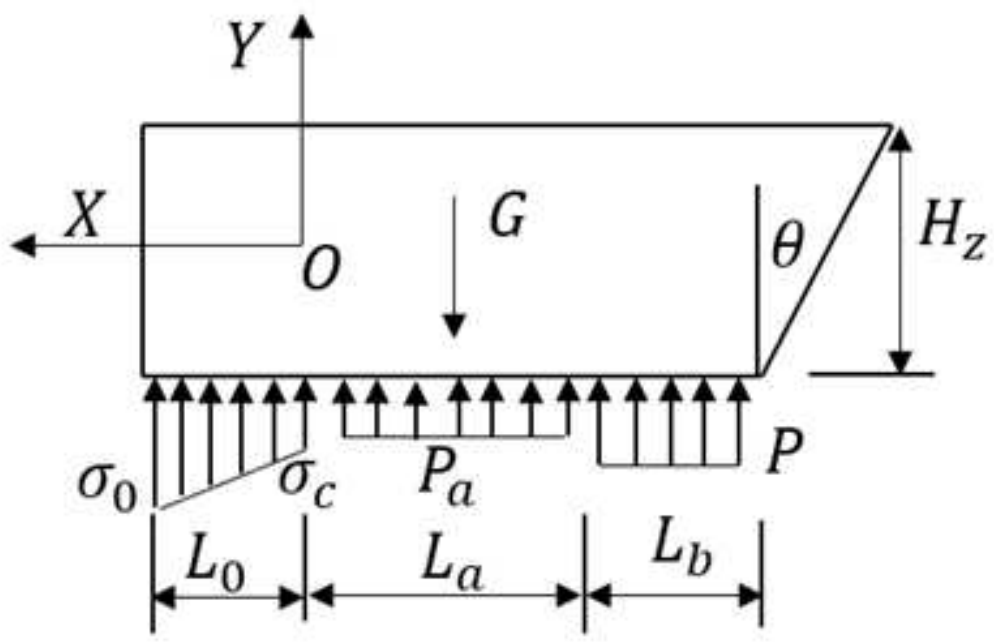

Figure 5 Mechanical model of the cantilever beam

After cutting the roof to form the "short-arm beam" structure, the mechanical model of the cantilever beam after the roof cutting is established in order to analyze the support resistance of the hydraulic support, as shown in Fig. 5:

According to the stress conditions of the structure, the static equilibrium equation can be obtained:

$$
\sum F=0
$$

and then

$$
\begin{gathered}
G=P_{a} L_{a}+P L_{b}+\frac{1}{2}\left(\sigma_{0}+\sigma_{c}\right) L_{0} \\
\sum M_{0}=0
\end{gathered}
$$

and then

$$
\begin{aligned}
& G \frac{\left(L_{0}+L_{a}+L_{b}\right)^{2}+\left(L_{0}+L_{a}+L_{b}+H_{z} \tan \theta\right)^{2}+\left(L_{0}+L_{a}+L_{b}\right)\left(L_{0}+L_{a}+L_{b}+H_{z} \tan \theta\right)}{3\left(2 L_{0}+2 L_{a}+2 L_{b}+H_{z} \tan \theta\right)} \\
& =P_{a} L_{a}\left(L_{0}+\frac{1}{2} L_{b}\right)+P L_{b}\left(\frac{1}{2} L_{b}+L_{0}+L_{a}\right)+\frac{1}{6}\left(2 \sigma_{c}+\sigma_{0}\right) L_{0}^{2}
\end{aligned}
$$

Where $G$ is rock mass gravity; $\sigma_{0}$ is interface stress of coal seam in the stress limit area of coal body; $\sigma_{c}$ is support stress of coal body to roof at roadway side; $P_{a}$ is support load in the roadway; $P$ is the support resistance of the hydraulic support. The support resistance of hydraulic support can be calculated, so as to verify the cutting effect according to formula (1) and (2).

\subsection{Supporting mechanism of surrounding rock in main roadway}

There is a stress transmission path in the direct roof and the basic roof above the goaf and the overlying rock layer on the retracement channel when the roof is not cut. The mining pressure will transfer to the depth of the surrounding rock along the transfer path with the further collapse of the goaf. There is a high concentration of stress above the coal pillar and the main roadway in the mining 
area. The coal pillar and the main roadway are in the high stress area, the coal pillar is crushed and affects the stability of the main roadway in the mining area as shown in Fig. 6.

The stress transmission structure of the roof rock mass can be changed by means of presplitting blasting and slotting the retracement channel. and the stress transmission path between the retracement channel roof and the goaf roof can be cut off, so that the main roadway in the mining area is in the pressure releasing area. To a certain extent, the problem of high stress concentration existing in the protection of coal pillars and the main roadway in the mining area can be avoided. The threat of high stress environment can be reduced as shown in Fig. 7.

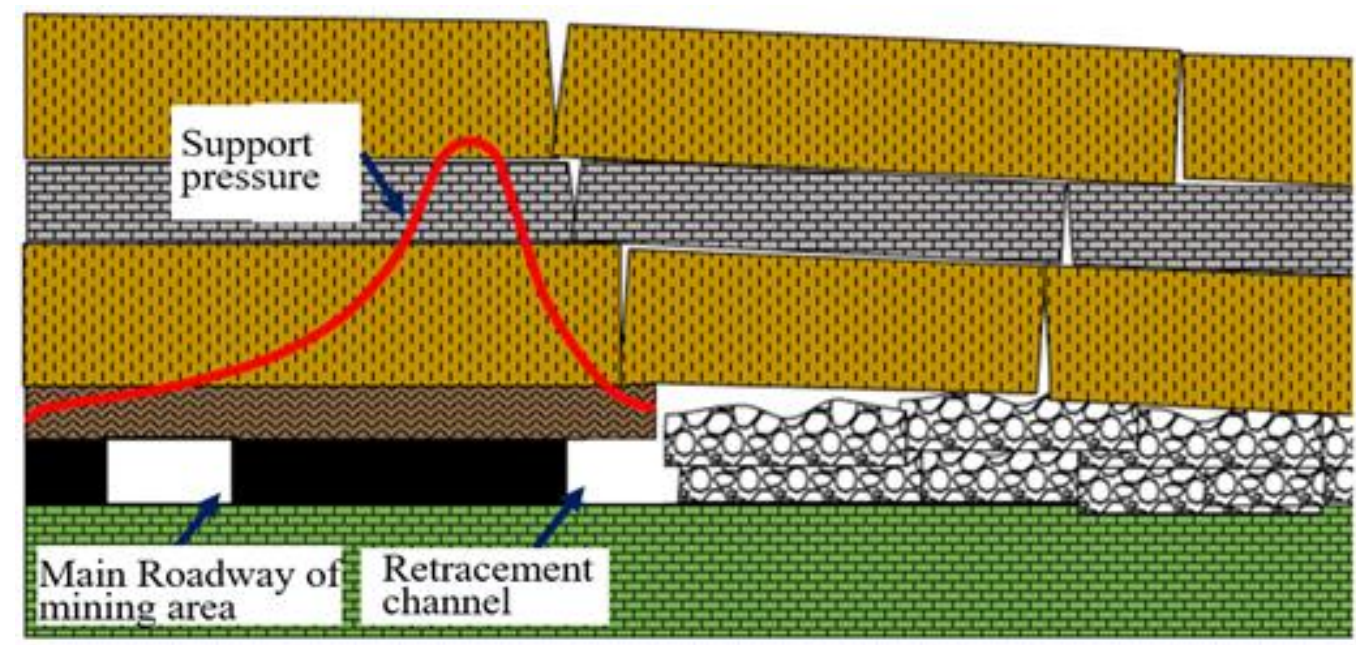

Fig. 6 Schematic diagram of support pressure transmission path without cutting

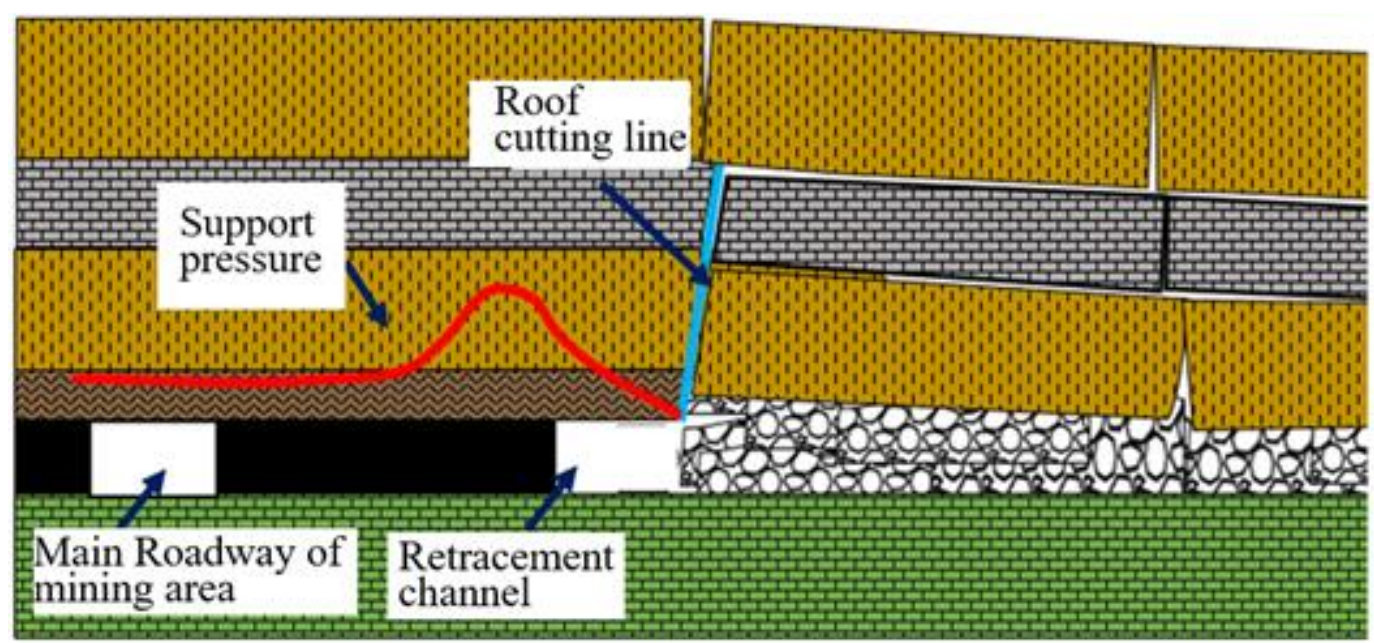

Fig. 7 Schematic diagram of support pressure transmission path after cutting 


\subsection{The technology of directional concentrated energy blasting}

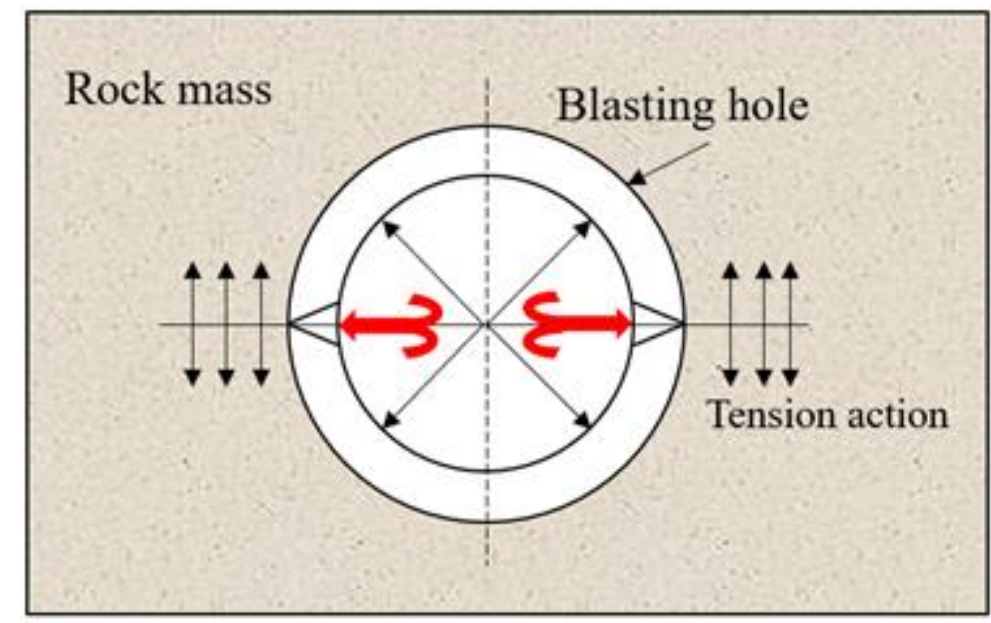

Fig.8 The model of bi-directional cumulative energy tension

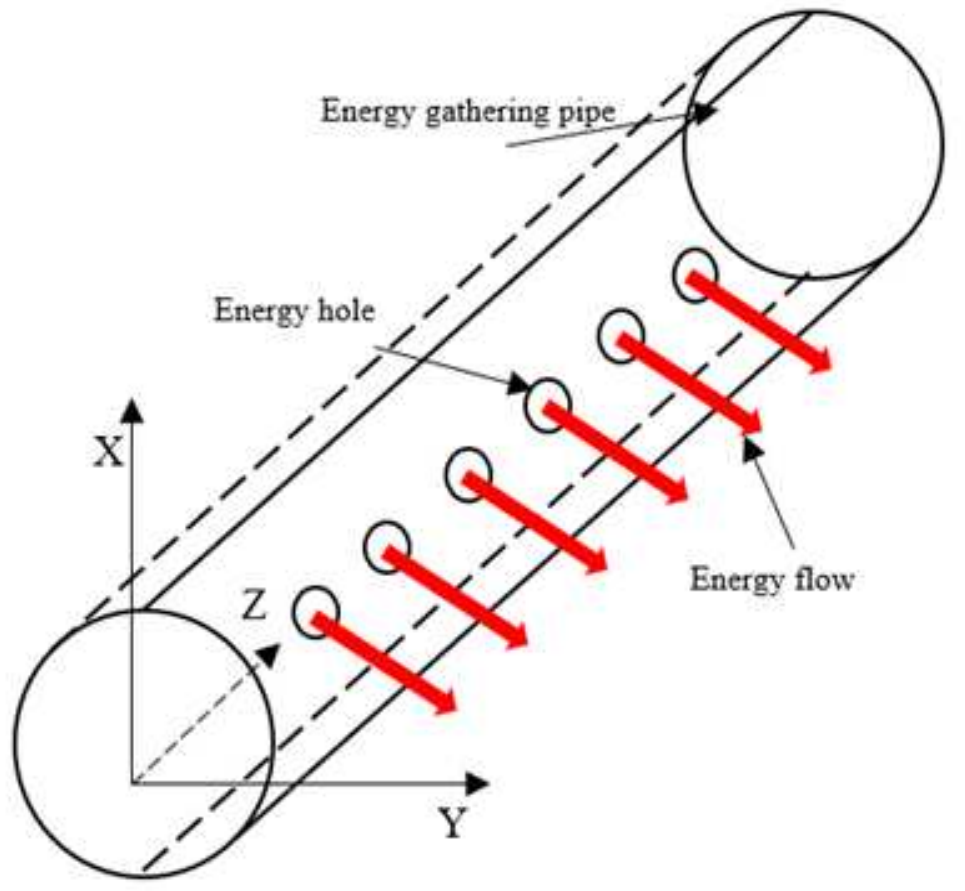

Fig. 9 Blasting control mechanism

The technology of directional cumulative energy blasting uses bi-directional cumulative energy device to achieve the tensile stress concentration produced by setting the fracture direction, and uses the concentrated stress to fracture the rock mass (Fig. 8). The bi-directional energy accumulation device makes use of the compression and tension resistance of rock mass. After the explosive detonates in the device, the detonation stress wave and detonation gas try to seek space to release energy. The stress wave and the explosive energy of the explosive gas are released from the energy hole, forming a high-speed energy flow under the guidance of the energy hole. Each energy gathering hole gathers a high energy flow to realize directional cutting (as shown in Fig. 9) [17]. In order to achieve the directional blasting effect, it is necessary to set the size, spacing and row spacing of the 
energy accumulation pipe according to the site lithology, rock mass structure and the original rock stress state of the construction rock mass.

\section{Roof cutting Design of key parameters for retracement channel}

\subsection{Theoretical design of key parameters}

\subsubsection{Design of roof cutting height}

The design of roof cutting height is generally determined according to the broken expand coefficient of the rock roof. The purpose is to fill the goaf with gangue after the roof is broken. The roof cutting height is calculated as follows [24]:

$$
H_{c}=\frac{H_{g}-\Delta H_{1}-\Delta H_{2}}{K-1}
$$

Where $\Delta H_{1}$ is the subsidence of roadway roof, $\mathrm{m} ; \Delta H_{2}$ is the floor heave of roadway, $\mathrm{m} ; \mathrm{K}$ is the broken expand coefficient, ranging from 1.1 to 1.5 ;

According to the roof slate property and actual site conditions of 3314 working face in Hexi coal mine, $\mathrm{K}$ in this design is 1.20 , the floor heave of the roadway is $0.1 \mathrm{~m}$, the roof subsidence is $0.2 \mathrm{~m}$, the retracement channel height is $2.4 \mathrm{~m}$, and the calculated cutting height is $10.5 \mathrm{~m}$.

According to the calculated cutting results, the cutting thickness of the roof is far greater than the mining height, and the pre-split cutting height does not penetrate the whole rock stratum. The end of the roof will contact with the rock in the goaf, resulting in the roof may not fracture. In order to break the whole rock stratum, the tensile force $\sigma$ of the non-penetrating surface is:

$$
\sigma=\frac{M(x)}{W}
$$

Where $M(x)$ is the bending moment in the pre-splitting cut-top not penetrating the face rock beam, and

$$
M(x)=\frac{1}{2} P(x)\left(L_{0}+L_{a}+L_{b}\right)-\frac{1}{2} q\left(L_{0}+L_{a}+L_{b}\right)^{2}-\frac{q\left(M_{p}-M\right)}{4 J g}\left(L_{0}+L_{a}+L_{b}\right)^{3}
$$

Where $J$ is the moment of inertia of the roof rock around point $\mathrm{O} ; W$ is the cross-sectional modulus of the roof. and

$$
W=\frac{\left(m_{s}+h_{c}\right)^{2}}{6}
$$

From the above calculation and analysis, it can be seen that the tensile force $\sigma$ of the pre-split cutting roof not penetrating the surface is determined by the roof cutting height. Therefore, the roof cutting height should meet the fracture of the top strata and the gangue can well fill the goaf after the roof fracture. Finally, the roof cutting height of 3314 retracement channel is $11.5 \mathrm{~m}$. 


\subsubsection{Design of roof cutting angle}

Before the roof collapses, a hinge structure will be formed between the blocks, and the cut structure surface will form an angle $\theta$ with the vertical surface, as shown in Fig. 10. When the block B slides downward, due to the horizontal pressing force $\mathrm{T}$, the block A generates a sliding resistance along the contact surface of block $\mathrm{B}$, that is the friction resistance $f_{k}$, and the value is [25]:

$$
f_{k}=(T \cos \theta-R \sin \theta) \tan \varphi
$$

The sliding force of block B on the contact surface:

$$
f_{h}=R \cos \theta+T \sin \theta
$$

if $f_{h} \geq f_{k}$, sliding and instability occurs at the articulation joint, that is:

$$
\left\{\begin{array}{c}
T \sin (\varphi-\theta) \leq R \cos (\varphi-\theta) \\
\theta \geq \varphi-\arctan (\varphi-\theta)
\end{array}\right.
$$

When the slit angle satisfies the condition of equation (9), block B will slide down along the cutting top surface.

The roof cutting angle of the retracement passage of 3314 working face in Hexi coal mine mainly meets the following three conditions:

(1) The friction force of the roof cutting surface should be small to meet the roof collapse of the goaf and achieve the pressure releasing effect.

(2) After cutting the top, the block B can't slide down immediately, so as to avoid frame pressing. There should be a certain buffer time for moving the frame.

(3) The roof cutting angle should not be too large, resulting in too much work.

Under the above three conditions, according to the actual geological conditions and construction conditions of Hexi coal mine, the roof cutting angle is determined to be $10^{\circ}$ by comprehensive analysis.
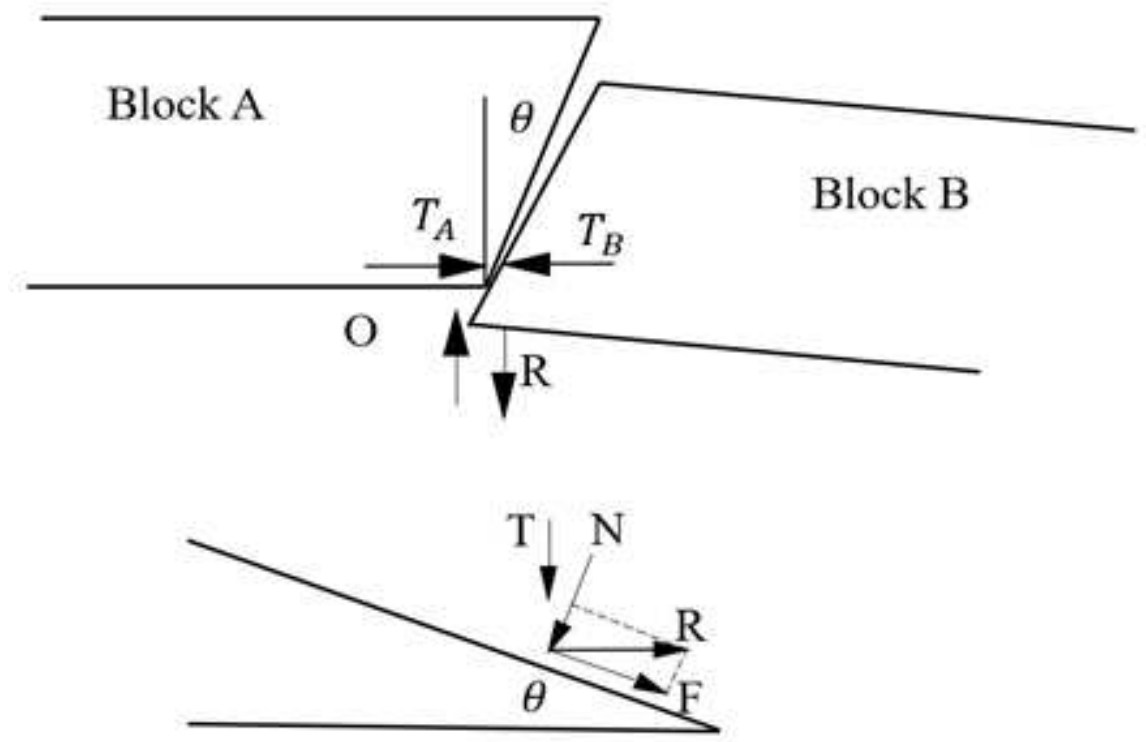

Fig. 10 The balance of the rock block joint 


\subsection{Numerical Simulation Analysis}

\subsubsection{Model establishment}

Based on the consideration of the actual engineering conditions and simplified calculations, the effect of cutting the roof of the retraction channel is analyzed. The calculation model was established using FLAC ${ }^{3 \mathrm{D}}$ numerical simulation software, and the constitutive model was selected from the Mohr-Coulomb model. The model dimensions are: length $\times$ width $\times$ height $=300 \mathrm{~m} \times 50 \mathrm{~m} \times 50 \mathrm{~m}$, and the average depth of the roadway is $400 \mathrm{~m}$. From top to bottom, the model is mudstone, sandy mudstone, siltstone, sandy mudstone, coal seam, and fine-grained sandstone, with thicknesses of $6 \mathrm{~m}$, $10 \mathrm{~m}, 1 \mathrm{~m}, 12 \mathrm{~m}, 2.4 \mathrm{~m}$, and $10 \mathrm{~m}$, respectively. The upper boundary of the model is subject to uniform self-gravity stress and horizontal compressive stress varying with depth. The calculation model is shown in Fig.11. The physical and mechanical parameters are shown in Table 1.

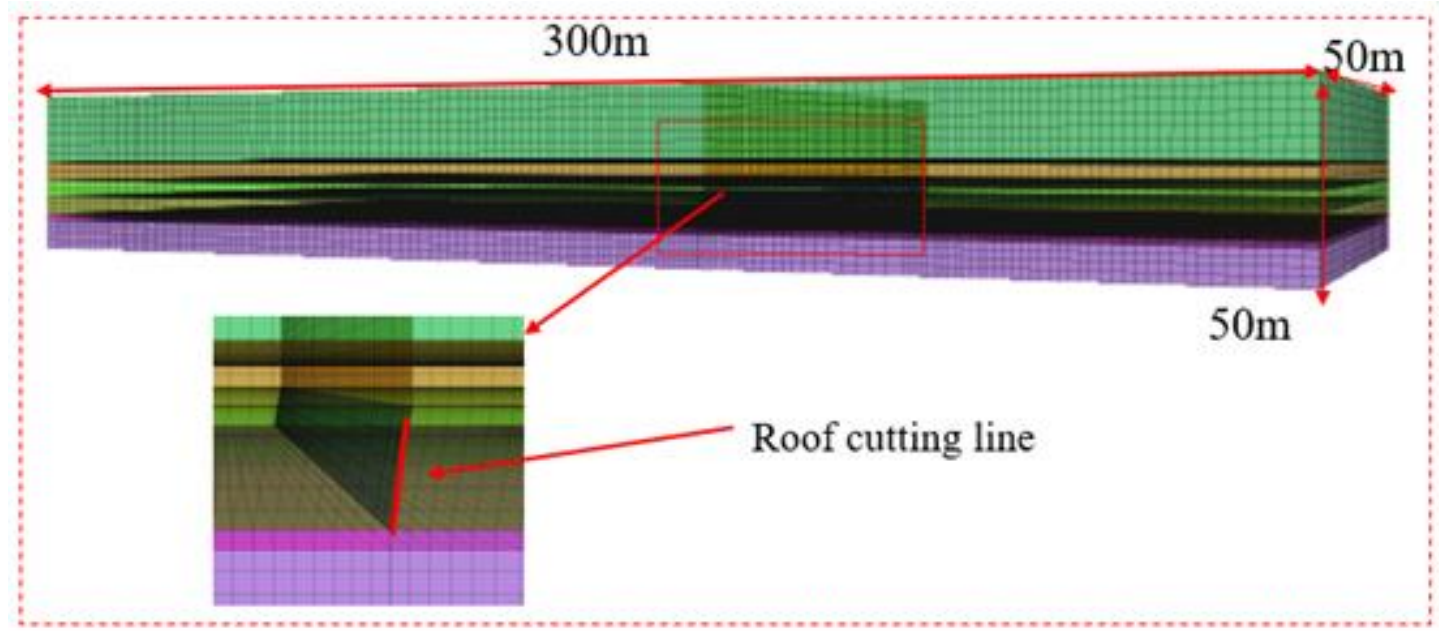

Fig. 11 Numerical calculation model

Table 1 Physical and mechanical parameters

\begin{tabular}{ccccccc}
\hline Lithology & $\begin{array}{c}\text { Density } \\
(\mathrm{kg} / \mathrm{m} 3)\end{array}$ & $\begin{array}{c}\text { Bulk modulus } \\
(\mathrm{GPA})\end{array}$ & $\begin{array}{c}\text { Shear modulus } \\
(\mathrm{GPA})\end{array}$ & $\begin{array}{c}\text { Friction } \varphi \\
\left({ }^{\circ}\right)\end{array}$ & $\begin{array}{c}\text { Cohesion } C \\
(\mathrm{MPa})\end{array}$ & $\begin{array}{c}\text { Tensile } T \\
(\mathrm{MPa})\end{array}$ \\
\hline $\begin{array}{c}\text { Sandy } \\
\text { mudstone }\end{array}$ & 2542 & 11.94 & 6.48 & 35 & 132 & 1.38 \\
Mudstone & 2589 & 7.02 & 1.03 & 24 & 930 & 1.21 \\
$\begin{array}{c}\text { Coal seam } \\
\text { Fine }\end{array}$ & 1312 & 3.95 & 3.22 & 37 & 1.27 & 0.32 \\
sandstone & 2320 & 3.78 & 3.08 & 38.42 & 1.75 & 0.85 \\
\hline
\end{tabular}




\subsubsection{Analysis of numerical simulation results}

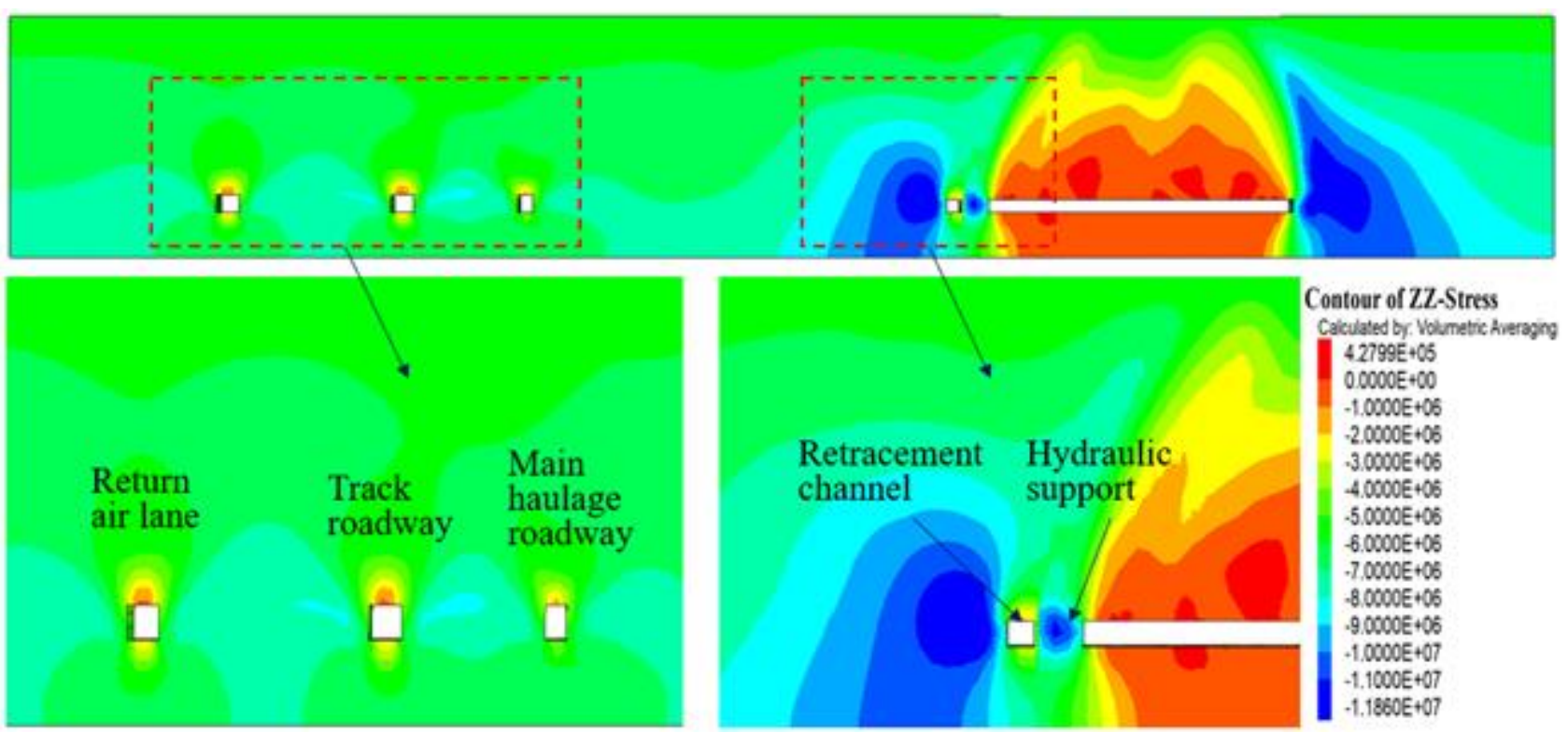

(a) No roof cutting and no evacuation of hydraulic support

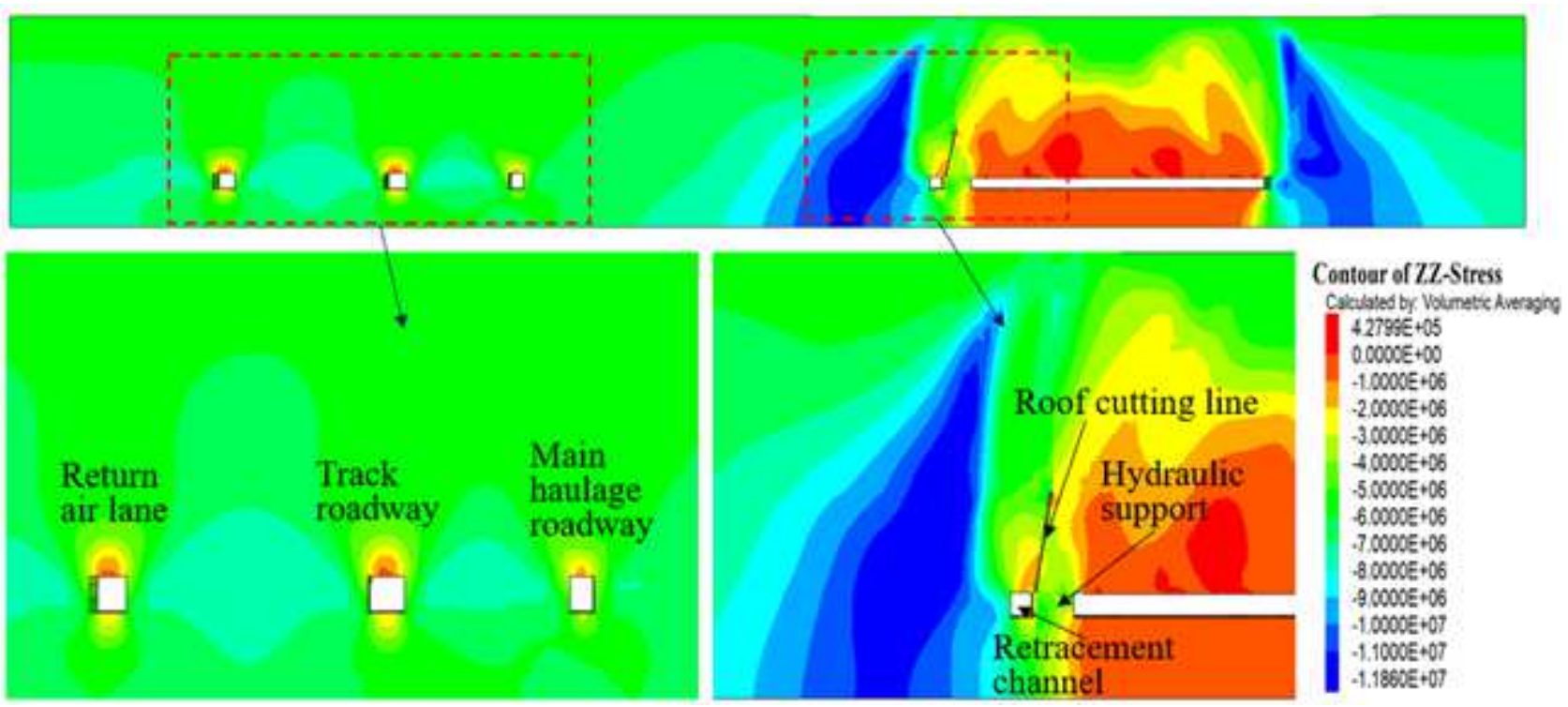

(b) Roof cutting and no evacuation of hydraulic support 


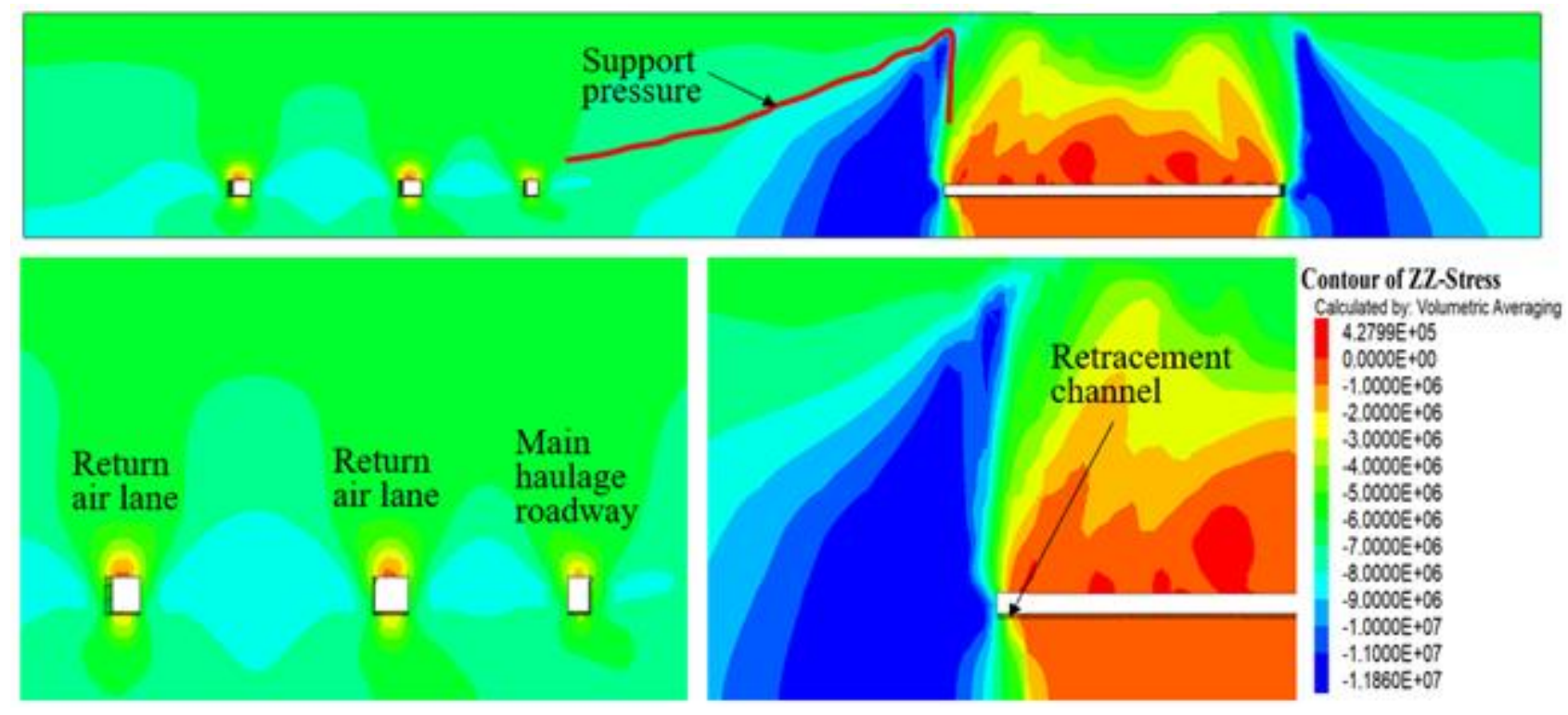

(c) No roof cutting and evacuation of hydraulic support

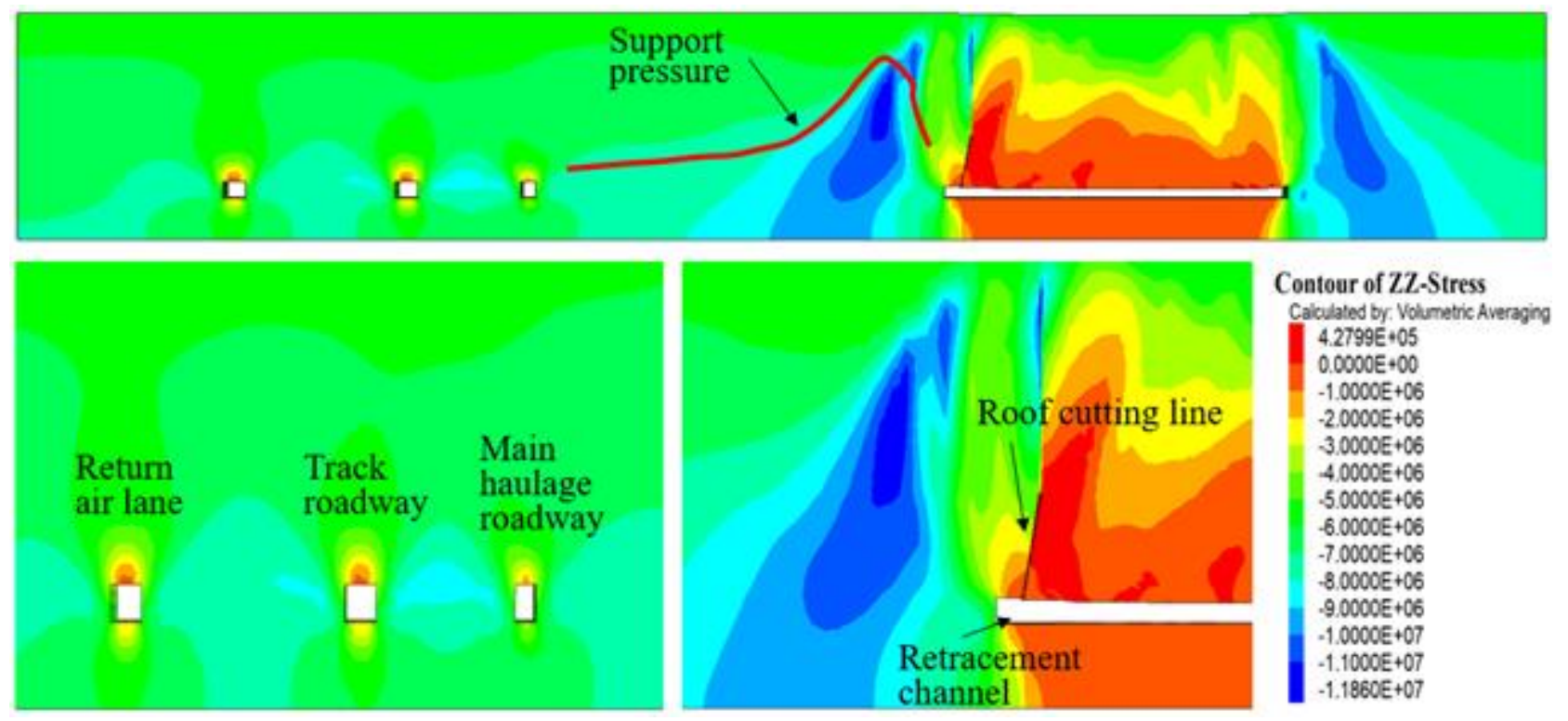

(d) Roof cutting and evacuation of hydraulic support

Fig. 12 Numerical calculation results of vertical stress distributions.

The vertical stress above the retracement channel is relatively large, with a value of $3.8 \mathrm{MPa}$ when the top is not cut, as shown in Fig. 12(a). There is obvious stress concentration in solid coal wall and hydraulic support. The vertical stress above the hydraulic support is too large, which is easy to cause the press frame accident. The stress of surrounding rock around the retracement tunnel is large, so it needs a large support resistance to ensure the deformation of surrounding rock in the controllable range, so as to ensure the safe and smooth evacuation of related equipment.

It can be seen from Figure 12 (b) that the vertical stress above the retreat channel is reduced, with a value of $1.5 \mathrm{MPa}$. The stress concentration of the hydraulic support is transferred to one side of the solid coal wall, which greatly reduces the vertical stress above the hydraulic support. The stress concentration of the solid coal side is shifted to the direction of the solid coal side. The stress of the 
surrounding rock of the retracement channel is reduced, and the deformation of the surrounding rock is reduced. When the rack is not removed, the impact of the cut and uncut roofs on the alley is basically the same.

In the case of no roof cutting, there is an obvious stress concentration area inside the solid coal slope after the support is withdrawn, and the maximum vertical stress is $11.8 \mathrm{MPa}$ (Fig. 12c). The stress concentration area has a large range, which has affected the location of the main roadway. There is still a high vertical stress in a certain range above the main roadway, with an average of $1.5 \mathrm{MPa}$. Among them, the vertical stress above the main haulage roadway closest to the goaf is the largest, with a value of $2.1 \mathrm{MPa}$. At the same time, there is obvious stress concentration in the coal pillar between the three main roadways, which is easy to cause the deformation of the roadways and is not conducive to the stability of the roadways.

From the vertical stress distribution in Figure 12 (d), it can be seen that under the condition of cutting the top, after the hydraulic support is retracted, the internal stress concentration pressure of the solid coal gang decreases, and the maximum vertical stress is about $10.5 \mathrm{MPa}$. The stress concentration range of the solid coal wall is obviously reduced, and the influence on the main roadway is reduced, so that the vertical stress above the roadway is reduced. The average value of the vertical stress is about $1.0 \mathrm{MPa}$. The maximum vertical stress above the main haulage roadway closest to the goaf is $1.5 \mathrm{MPa}$. The stress size and the stress concentration range of the coal pillar between the roadways are also significantly reduced. It plays a positive role in roadway maintenance and surrounding rock stability.

The technology of directional roof cutting can effectively cut off the stress transmission path between the roadway and the roof of the goaf, so as to reduce the internal stress concentration phenomenon of the solid coal side. Not only the stress peak is greatly reduced, but also the stress concentration area is moved away from the roadway side and transferred to the deep position of the solid coal side. The continuity of roadway and goaf roof is cut off, which makes it have independent deformation characteristics. The roof of the roadway forms a short-arm beam structure, and the rotation deformation is reduced, so that the deformation of the roof of the roadway is effectively controlled.

\subsection{Design scheme of retracement channel}

According to the roof conditions of the retracement channel, the cut roof construction area is divided into three areas, namely area I, area II and area III, as shown in Fig. 13. The roof of area I and area III is relatively broken, and the distance between cutting holes is $1000 \mathrm{~mm}$. The roof integrity of area II is good, and the distance between cutting holes is $750 \mathrm{~mm}$. Based on the calculation and numerical analysis of key cutting parameters, the cutting scheme of Fig. 14 was designed. 


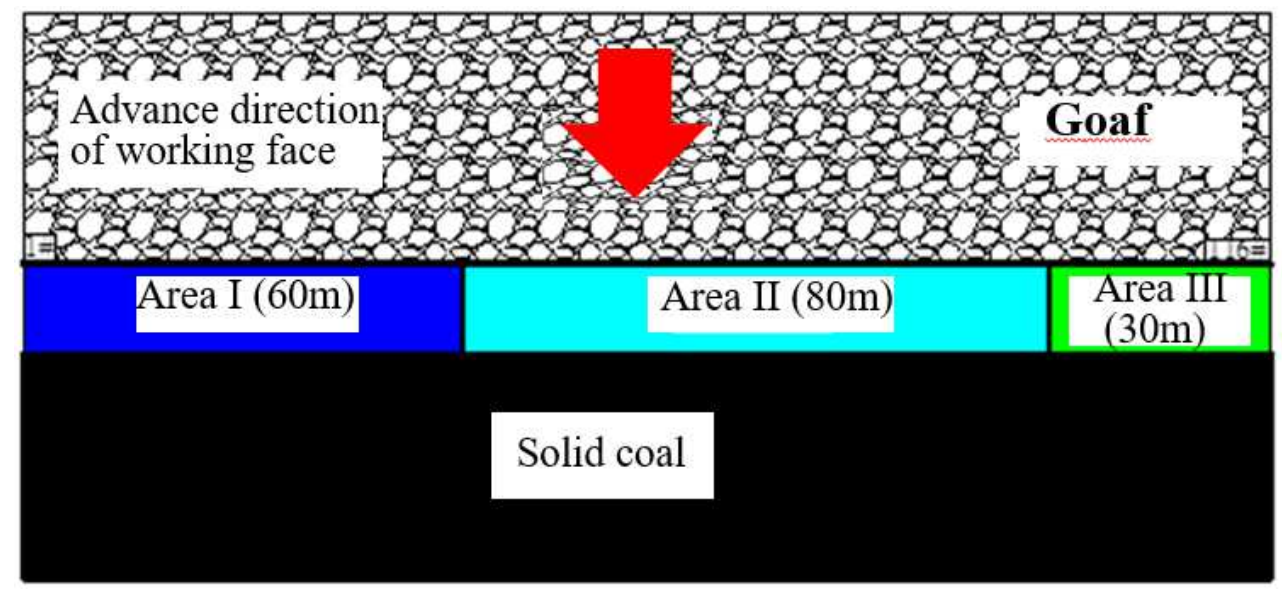

Fig. 13 Schematic diagram of roof cutting partition

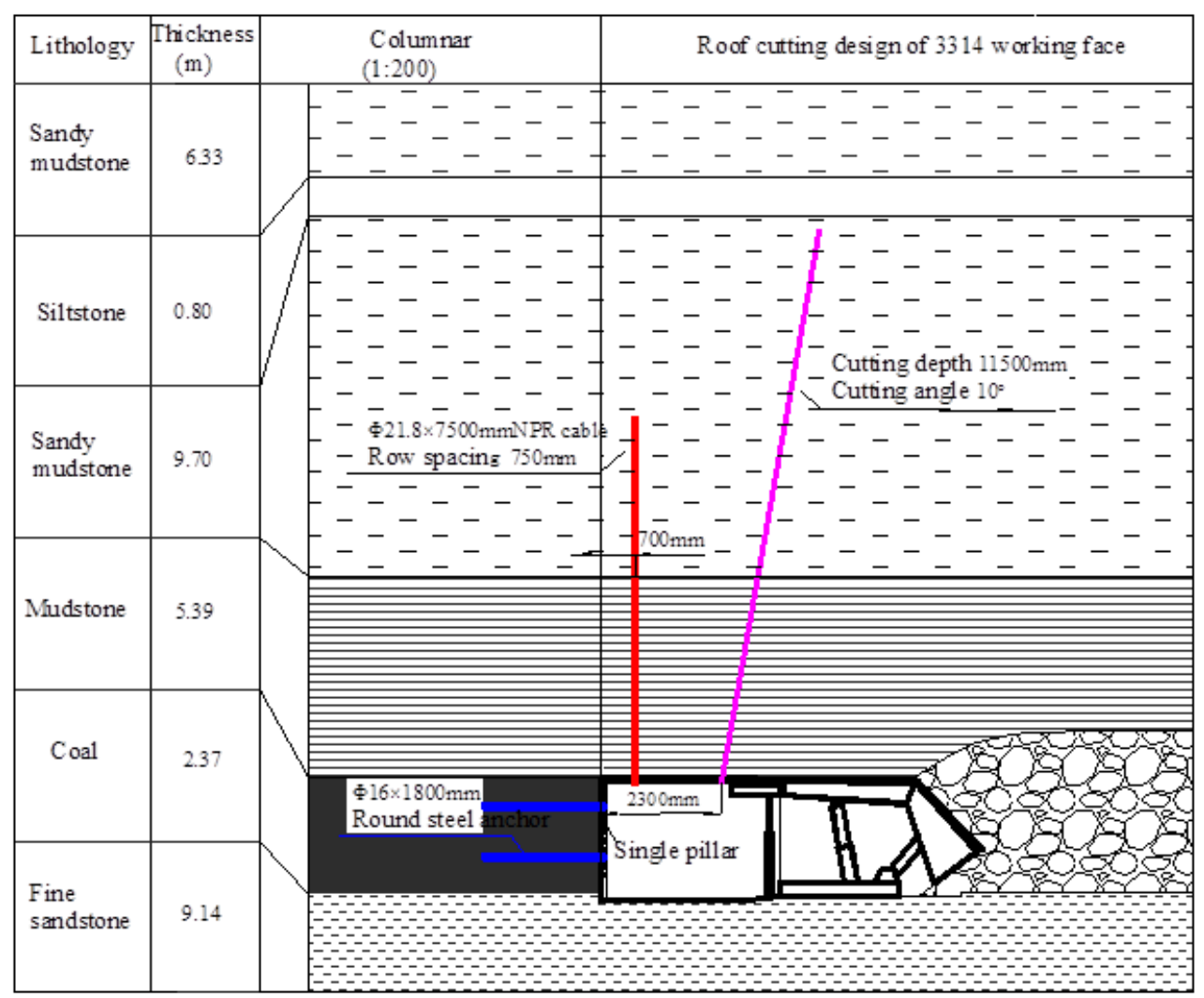

Fig. 14 Roof cutting design of retracement channel

\section{Field engineering test}

\subsection{Site construction}

Construction process of the retracement channel roof cutting: (1) Reinforcement support. According to the designed support parameters, the retracement channel is pre-installed with constant resistance anchor cable. The anchor cable is combined with the original single support to the roadway, as shown in figure 15. Reinforcement support is mainly to reduce the impact of the roof cutting on the retreat channel and ensure the stability of the roof. (2) Drilling and charging detonation. First of all, the drilling construction is carried out, and the cutting hole is kept in a straight line as far as 
possible. Then charge and detonate, the number of each initiation can not exceed the limit, and 3-5 holes are more suitable, as shown in Fig. 16.
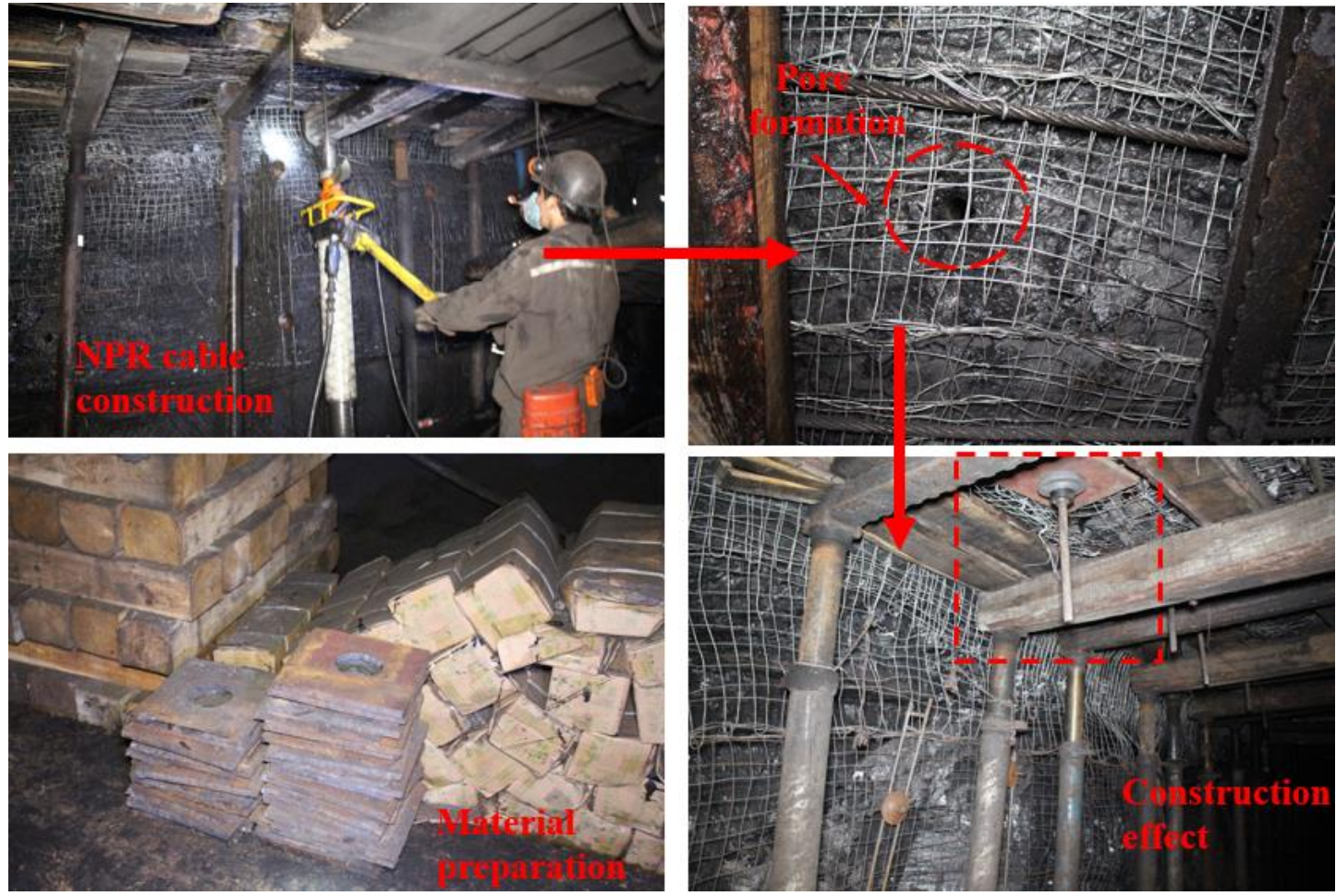

Fig. 15 Construction of reinforcement support
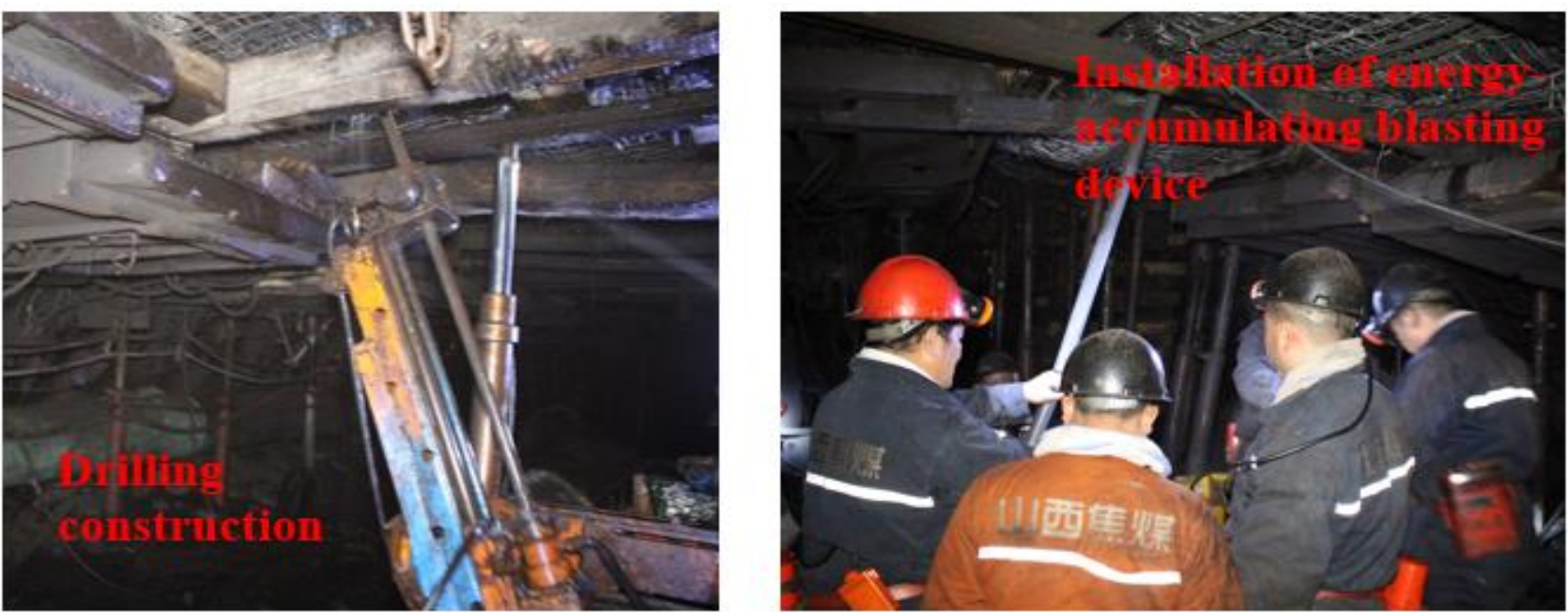

Fig.16 Cutting and charging construction

\subsection{Monitoring results}

In order to verify the effect of roof cutting and pressure releasing, the deformation of the retracement channel after cutting and deformation of the main roadway after penetration were monitored. Five measuring points are arranged in the retracement channel and the main roadway respectively. The deformation observation of the retracement channel is from the roof cutting to the connection between the working face and the withdrawal channel. The deformation observation of 
the main roadway starts from the working face and the back channel are connected and ready to remove hydraulic support.

It can be seen from the deformation monitoring curve of the retracement channel in Fig. 17 that the roof to floor convergence and two sides convergence begin to increase sharply at the position where the working surface is about $30 \mathrm{~m}$ away from the retracement channel. The deformation of the roof to floor and the two sides began to decrease at a distance of about $10 \mathrm{~m}$ from the retracement channel. The deformation of the retracement channel increases when the working face is completely connected with the retracement channel. According to the observation, the maximum roof to floor convergence is $141 \mathrm{~mm}$, and the two sides convergence is $79 \mathrm{~mm}$.

The deformation of the surrounding rock in the main roadway is relatively small in the early stage of the evacuation of the hydraulic frame, as shown in Fig. 18. With the completion of the hydraulic support retraction, the rock pressure at the roof began to be completely borne by the solid coal side. The deformation of the main roadway increases rapidly in the 30 days after the hydraulic support is completely evacuated. Then the deformation of the main roadway is small and tends to be stable. the maximum roof to floor convergence of the surrounding rock is $37 \mathrm{~mm}$, and the two sides convergence is $33 \mathrm{~mm}$.

Through field monitoring, it can be seen that the directional roof cutting technology can well control the deformation of retracement channel surrounding rock in the process of working face and retracement channel through and after through. This technology ensures the smooth and safe evacuation of related equipment. At the same time, because the stress transfer is cut off, the stability of the surrounding rock of the main roadway is guaranteed.

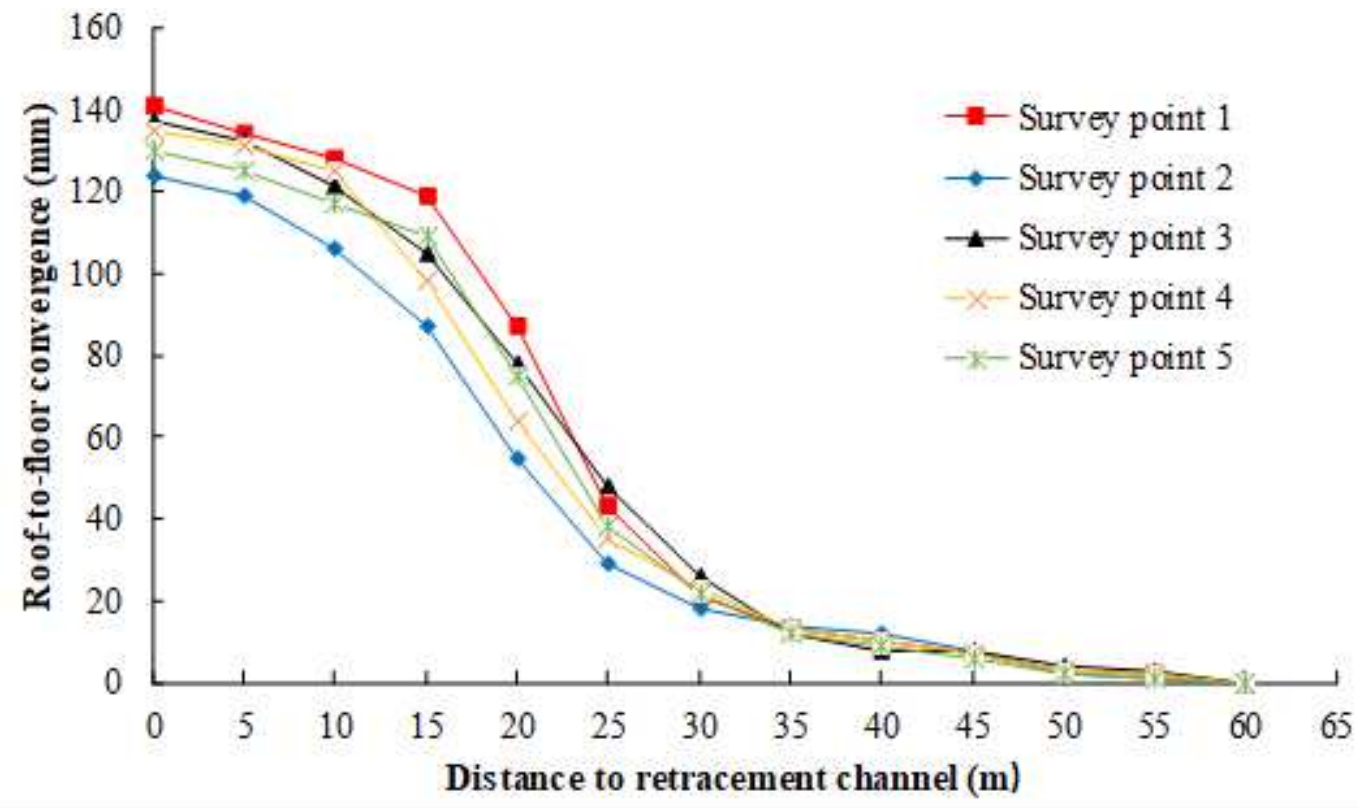

(a) 


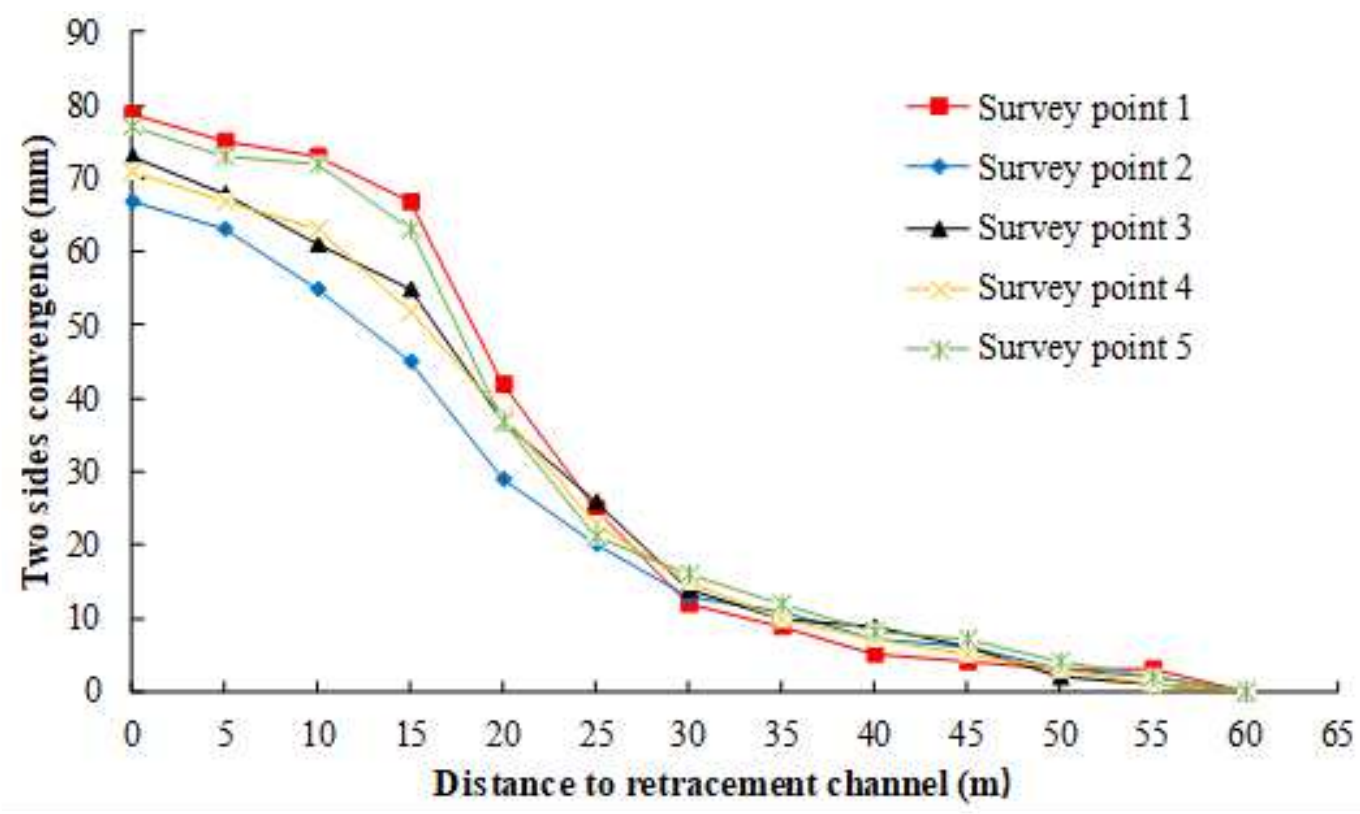

(b)

Fig. 17 Deformation of surrounding rock in retracement channel (a) roof to floor convergence (b) two side convergence

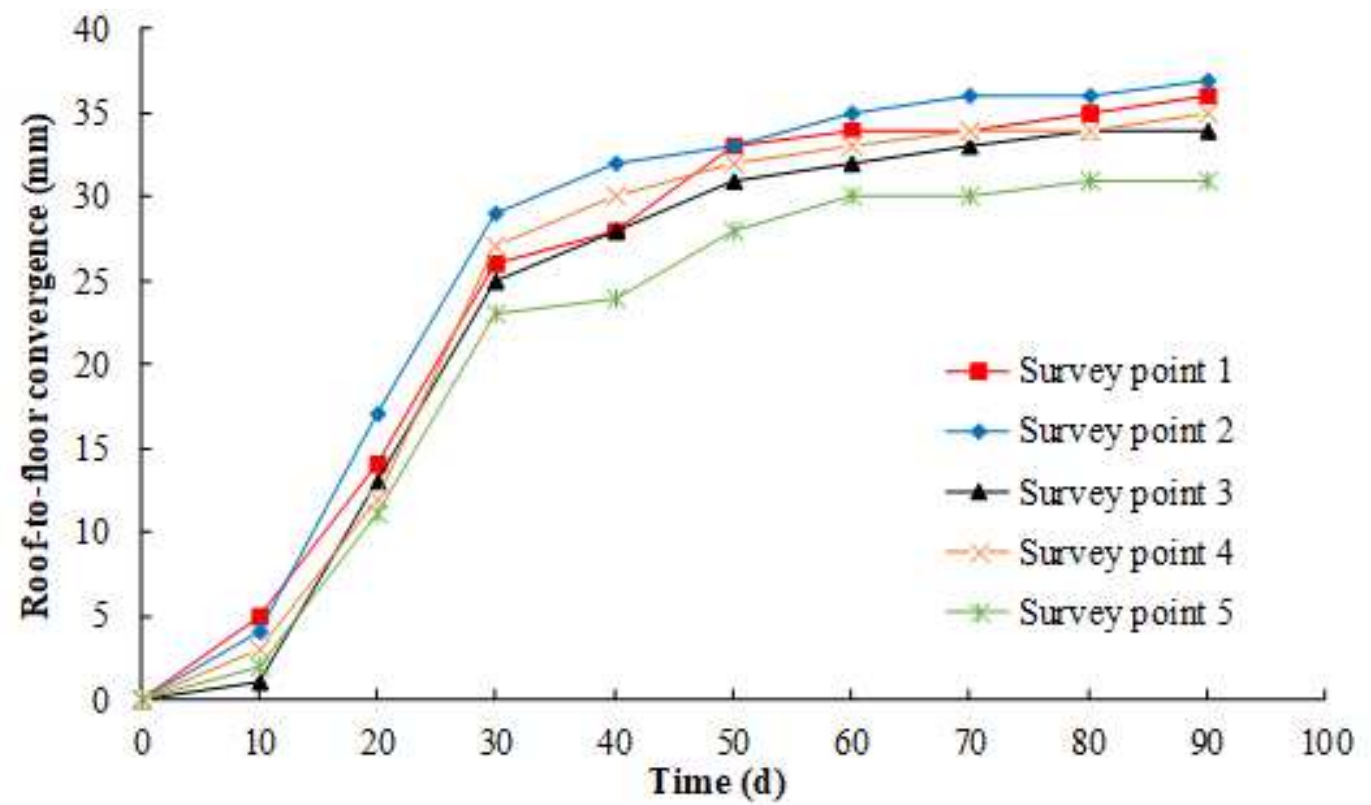

(a) 


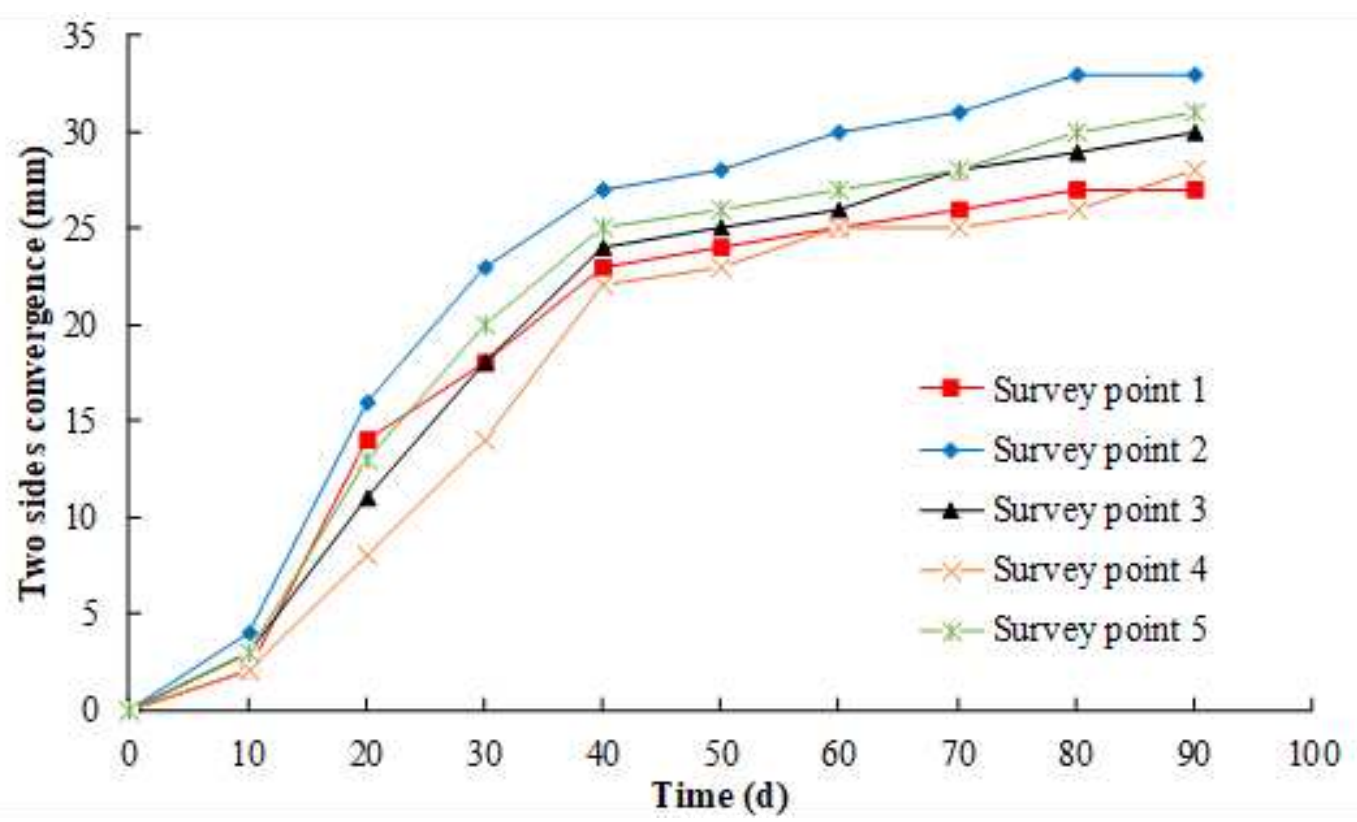

(b)

Fig. 18 Deformation of surrounding rock in the main roadway (a) roof to floor convergence (b) two side convergence

\section{Conclusion}

The high stress of the surrounding rock of Hexi Coal Mine easily leads to severe deformation of the retracement channel and the appearance of the mine pressure during the retreat severely affects the stability of the roadway. In order to solve the above problems, a roadway surrounding rock control technology is proposed and tested. The bidirectional energy-concentrated tensile blasting technology is used to perform directional cutting to cut off the stress propagation path. After the field test, the surrounding rock control effect is good. The main conclusions are as follows:

(1) The roof structure of the retracement channel is analyzed. The directional roof cutting changes the structure, from "long arm beam" structure to "short arm beam" structure. The roof cutting can effectively cut off the stress transmission path between the roadway and the roof of the goaf, and reduce the stress concentration in the solid coal side。 The stress peak of solid coal gang and hydraulic support is greatly reduced.

(2) The key parameters of cutting height and angle are analyzed. According to the field conditions of 3314 working face, and through theoretical calculation and numerical simulation analysis of its effect, it is concluded that the cutting height of 3314 retracement channel is $11.5 \mathrm{~m}$, and the cutting angle is $10^{\circ}$.

(3) The field application of the directional cutting technology shows that the cutting effect is good. In the process of connecting the working face and the retracement channel, the maximum roof to floor convergence is $141 \mathrm{~mm}$, and the two sides convergence is $79 \mathrm{~mm}$. After the hydraulic support was retracted, the maximum roof to floor convergence of the surrounding rock is $37 \mathrm{~mm}$, and the two sides convergence is $33 \mathrm{~mm}$. 


\section{Data Availability}

The data used to support the findings of this study are available from the corresponding author upon request.

\section{Conflicts of Interest}

The authors declare that they have no conflicts of interest.

\section{Acknowledgments}

This work is supported by the National Natural Science Foundation of China (No. 51904207), which are gratefully acknowledged.

\section{Reference}

Chen Y, Ma S, Yang Y et al (2019) Application of shallow-hole blasting in improving the stability of gob-side retaining entry in deep mines: a case study. Energies, 12(19), 3623.

Fei L, Jiang Z (2018) Research on deformation mechanism of retracement channel during fully mechanized caving mining in superhigh seam. Advances in Civil Engineering, 2018.

Gong P, Ma Z, Ni X et al (2018) An experimental investigation on the mechanical properties of gangue concrete as a roadside support body material for backfilling gob-side entry retaining. Advances in Materials Science and Engineering, 2018.

He MC, Ma X, Yu B (2019) Analysis of strata behavior process characteristics of gob-side entry retaining with roof cutting and pressure releasing based on composite roof structure. Shock and Vibration, 2019.

He MC, Zhu G, Guo Z (2015)Longwall mining “cutting cantilever beam theory” and 110 mining method in China-The third mining science innovation. Journal of Rock Mechanics and Geotechnical Engineering, 7(5), 483-492.

He MC, Chen SY, Guo ZB et al (2017) Control of surrounding rock structure for gob-side entry retaining by cutting roof to release pressure and its engineering application. J China Univ Min Technol, 46(5), 959-969.

Liqing D, Feng B, Guohua, L (2013) Fully mechanized coal mining face equipment quickly moving from one surface practice. Coal Mine Machinery, 34(12), 167-169.

Li YS, Liu YC (2010) Application of bolt and steel mesh support to equipment removing gateway of fully mechanized longwall coal mining face. Coal Science and Technology, 38(4), 35-36.

Ma JM, Shao MC, Shi JS (2016) Research on supports retracement process of fully mechanized coalmining face," Coal Science \& Technology Magazine, 44(1), 21-23. 
Peng H, Nie W, Cai P, et al (2019) Development of a novel wind-assisted centralized spraying dedusting device for dust suppression in a fully mechanized mining face. Environmental Science and Pollution Research, 26(4), 3292-3307.

Shu CX, Jiang FX, Han Y et al (2018) Research on rapid retracement technology of long distance multi-lane in deep heavy mining face. Journal of Mining \& Safety Engineering, 35 (03), 473 480.

Gu SC, Huang RB, Li, JH et al (2017) Stability analysis of remaining coal pillars during underground pressure adjustment before working face penetration. Journal of Mining \& Safety Engineering, 34 (01), 60-66.

Qiang X, Wang W, Wang F (2019) Distribution law of principal stress difference of deep surrounding rock of gob-side entry and optimum design of coal pillar width. Tehnički vjesnik, 26(6), 17431752.

Sun XM, Liu X, Liang GF et al (2014) Key parameters of gob-side entry retaining formed by roof cut and pressure releasing in thin coal seams. Chinese Journal of Rock Mechanics and Engineering, 33(7), 1449-1456.

Varden R, Lachenicht R, Player J et al (2008) Development and implementation of the Garford dynamic bolt at the Kanowna Belle Mine. In Proceedings of the 10th Underground operators conference (Vol. 19).

Wang G (2017) Study on deformation and failure mechanism of retracement channel in fully mechanized mining face. Coal Technology, 36 (07), 105-107.

Wang GJ, Zhao FJ, Tang HX et al (2013) Roof structure and support technology of retracement channel of fully mechanized mining face. Research of Mining Engineering, 28 (03), 15-19.

Wang C, Zhang C, Zhao X et al (2018) Dynamic structural evolution of overlying strata during shallow coal seam longwall mining. International Journal of Rock Mechanics and Mining Sciences, 103, 20-32.

Wang Q, He M, Yang J et al (2018) Study of a no-pillar mining technique with automatically formed gob-side entry retaining for longwall mining in coal mines. International Journal of Rock Mechanics and Mining Sciences, 110, 1-8.

Yuan Y, Tu S, Zhang X, et al (2013) System dynamics model of the support-surrounding rock system in fully mechanized mining with large mining height face and its application. International Journal of Mining Science and Technology, 23(6), 879-884.

Zhang GD, Yin F (2012) Study on safety withdrawing technology of hydraulic powered supports from fully mechanized coal mining face. Coal Science and Technology, 40(8), 14-17.

Zhu D, Tu S, Tu H et al (2019) Mechanisms of support failure and prevention measures under doublelayer room mining gobs-a case study: Shigetai coal mine. International Journal of Mining Science and Technology, 29(6), 955-962. 
Zhang Y, Yang Y, Zhug C (2019) Deformation caused by dynamic load and support requirements in a deep gob-side entry rock mass. Advances in Materials Science and Engineering, 2019. 
Figures

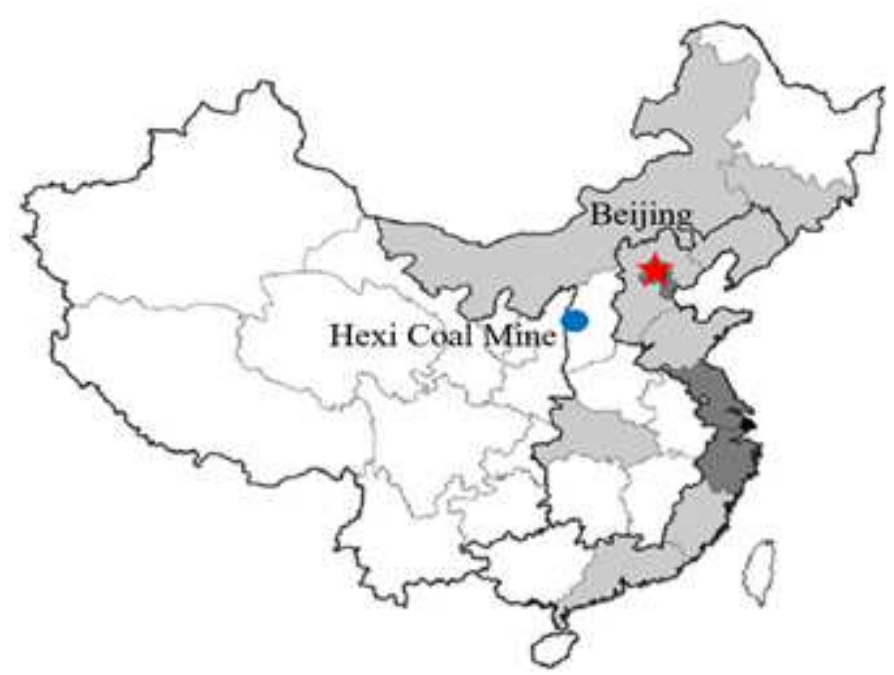

\section{Figure 1}

The location of the Hexi coal mine Note: The designations employed and the presentation of the material on this map do not imply the expression of any opinion whatsoever on the part of Research Square concerning the legal status of any country, territory, city or area or of its authorities, or concerning the delimitation of its frontiers or boundaries. This map has been provided by the authors. 


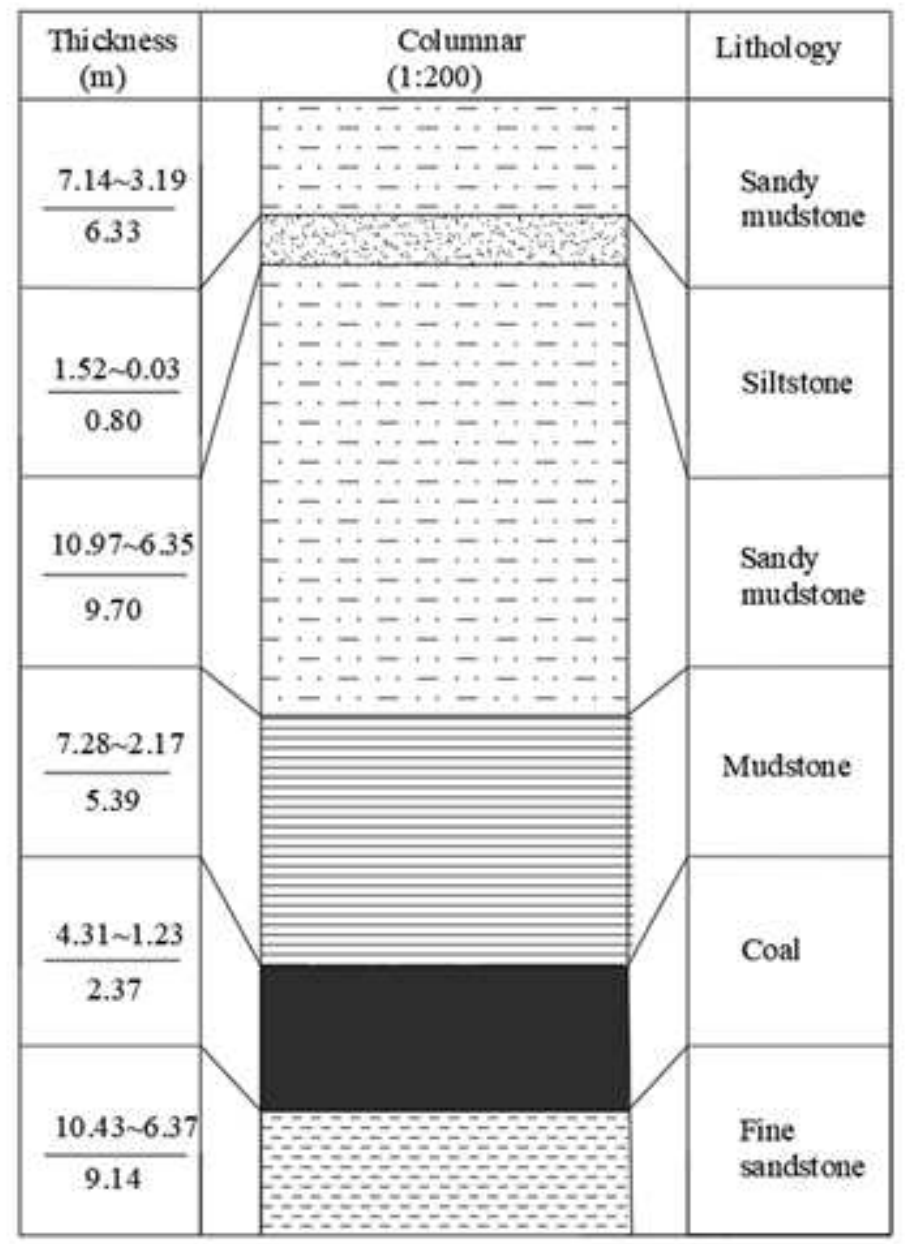

\section{Figure 2}

Stratigraphic histogram

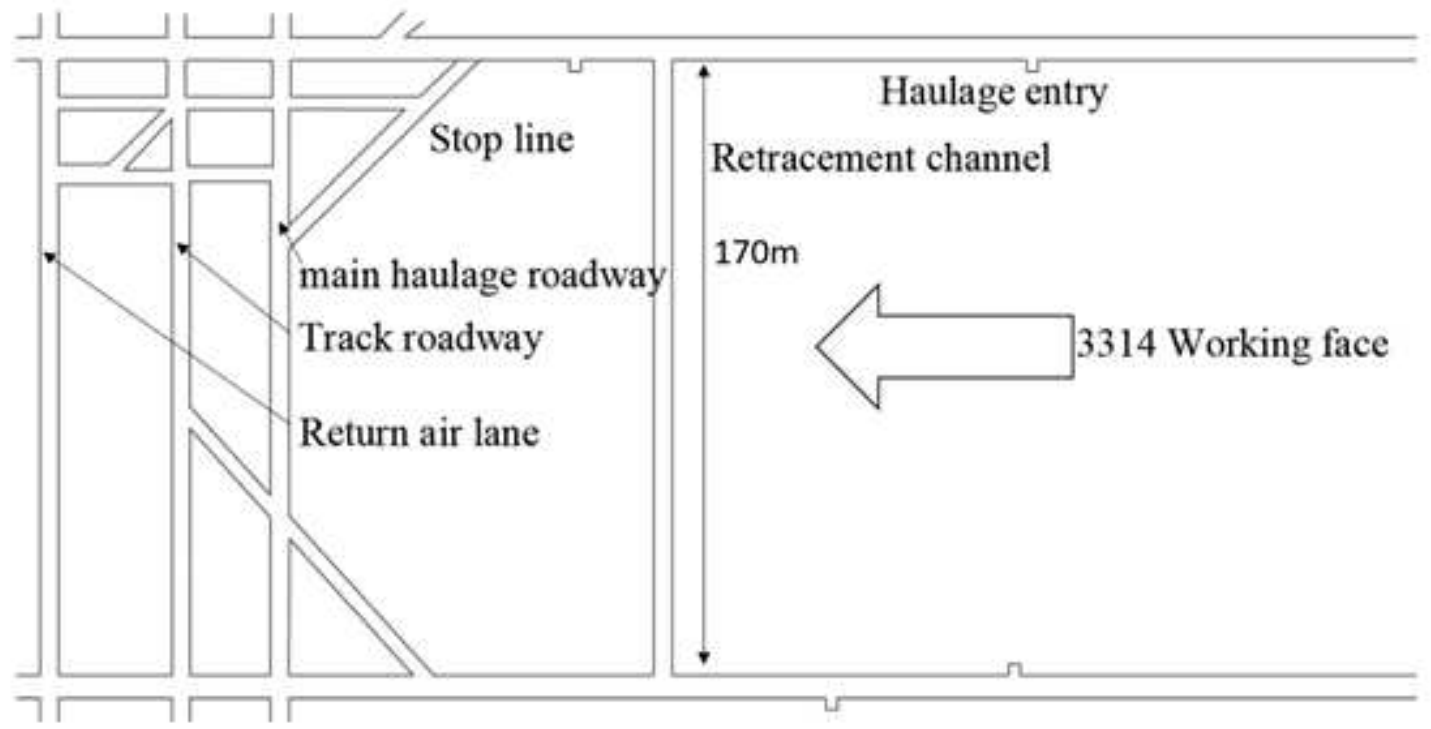

\section{Figure 3}

The layout of 3314 working face and roadway 


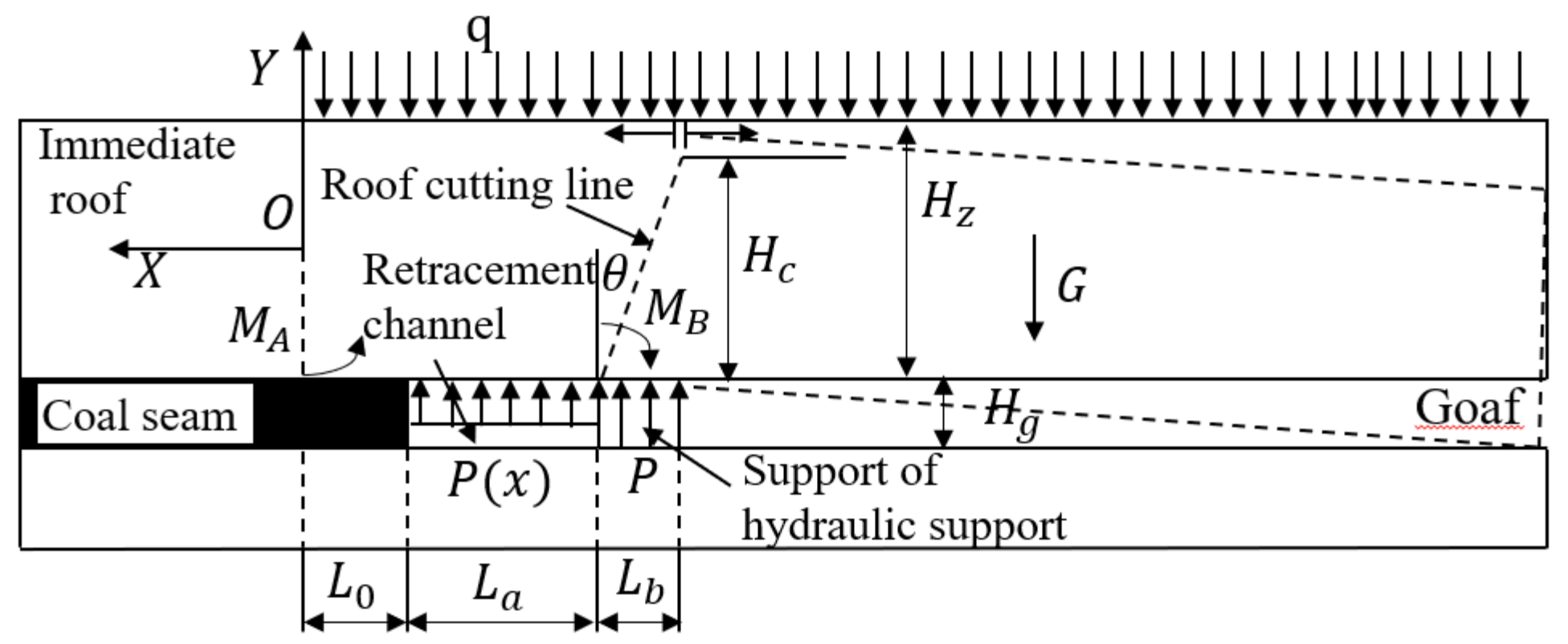

Figure 4

Mechanical model of retracement channel roof

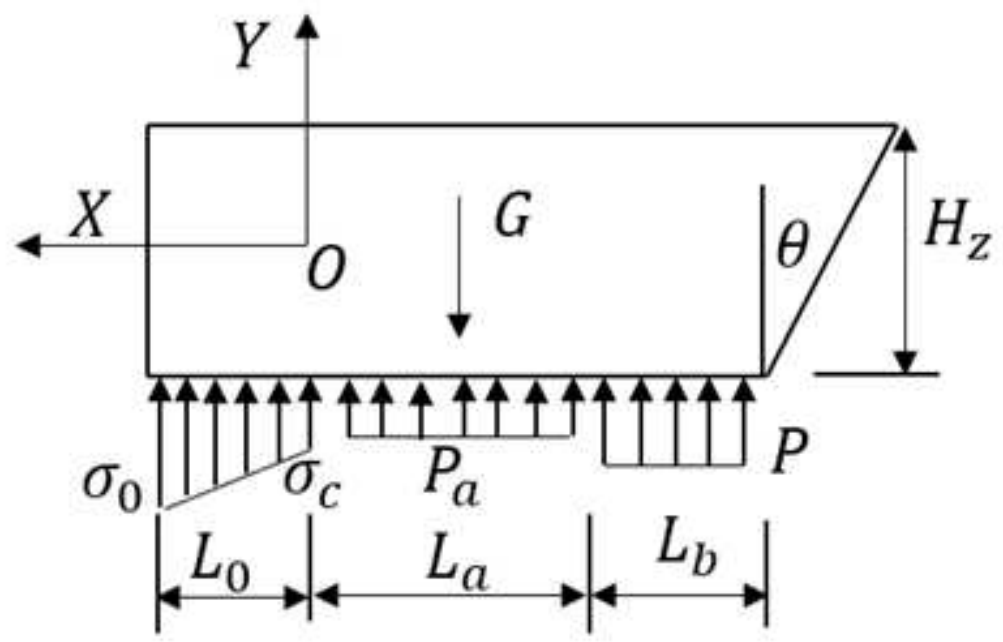

Figure 5

Mechanical model of the cantilever beam 


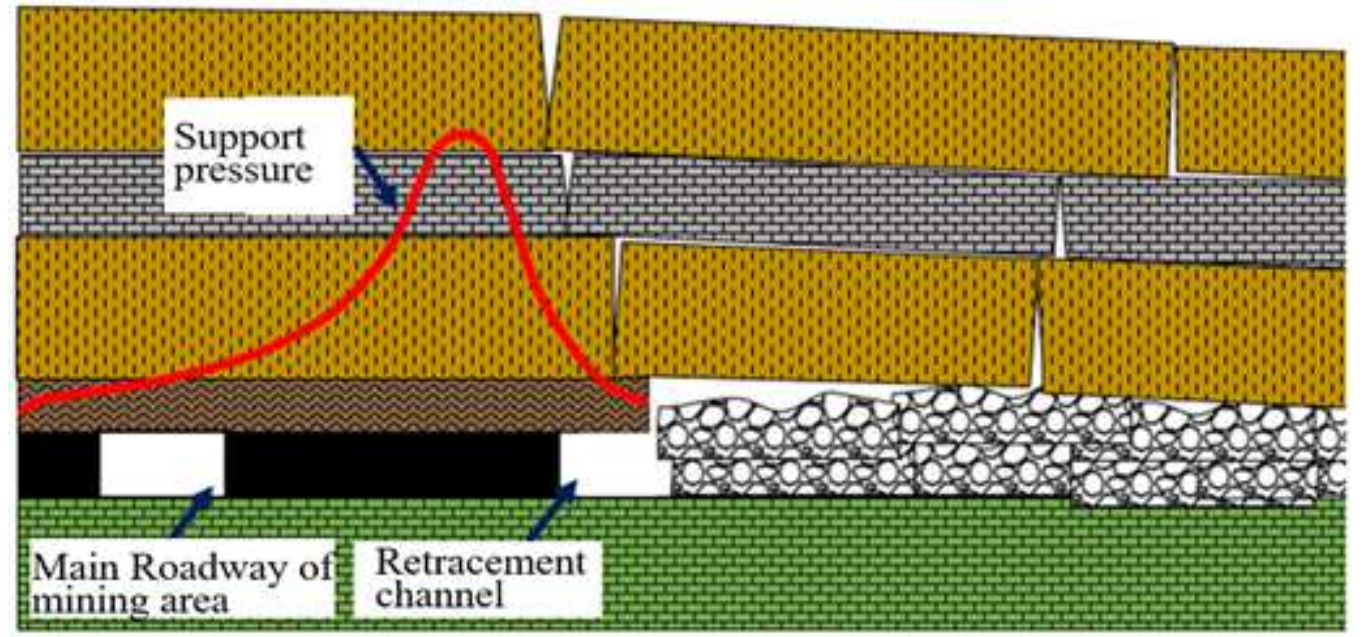

\section{Figure 6}

Schematic diagram of support pressure transmission path without cutting

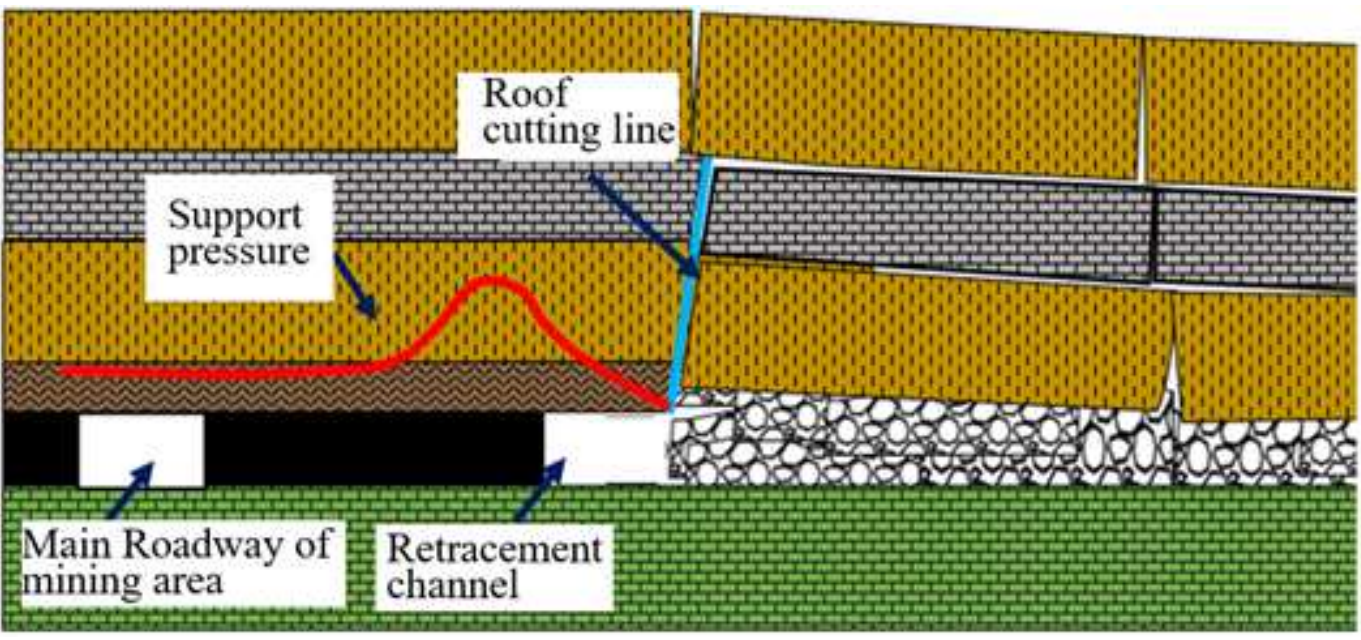

\section{Figure 7}

Schematic diagram of support pressure transmission path after cutting

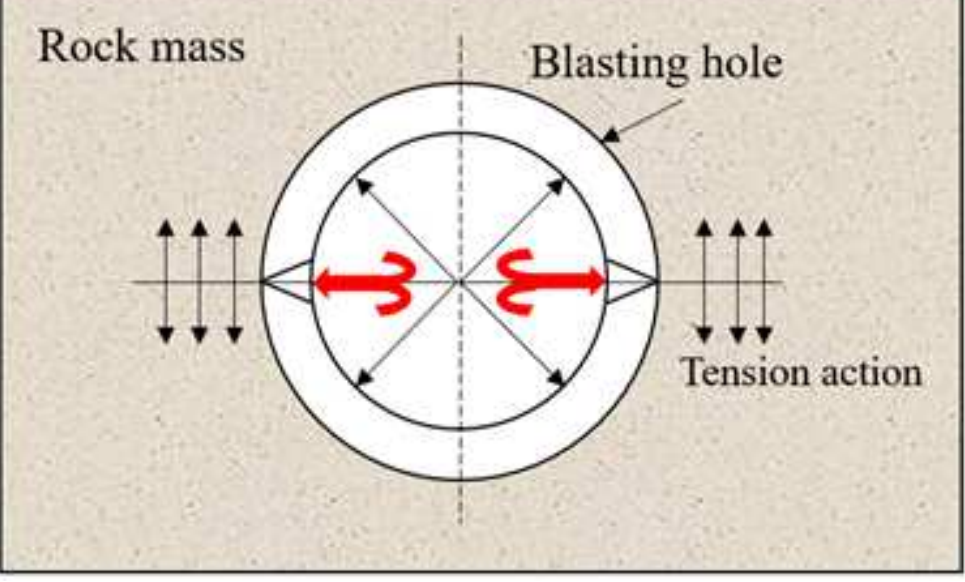

Figure 8 
The model of bi-directional cumulative energy tension

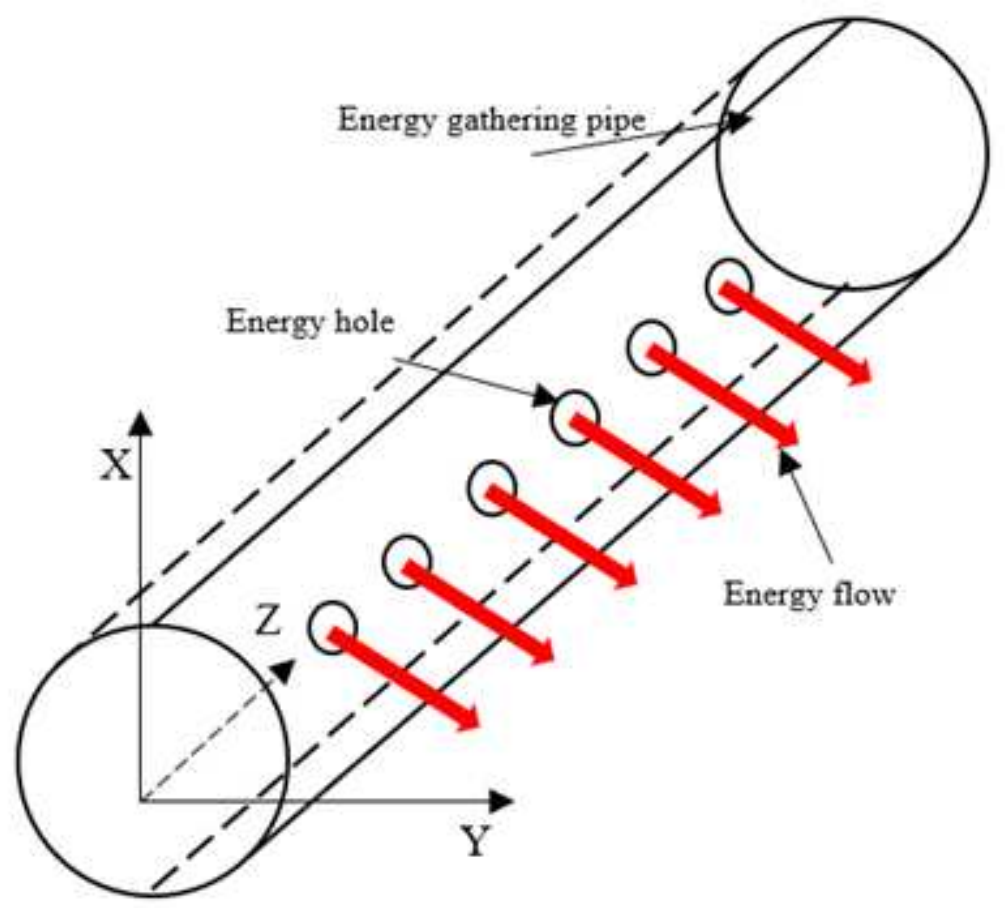

Figure 9

Blasting control mechanism
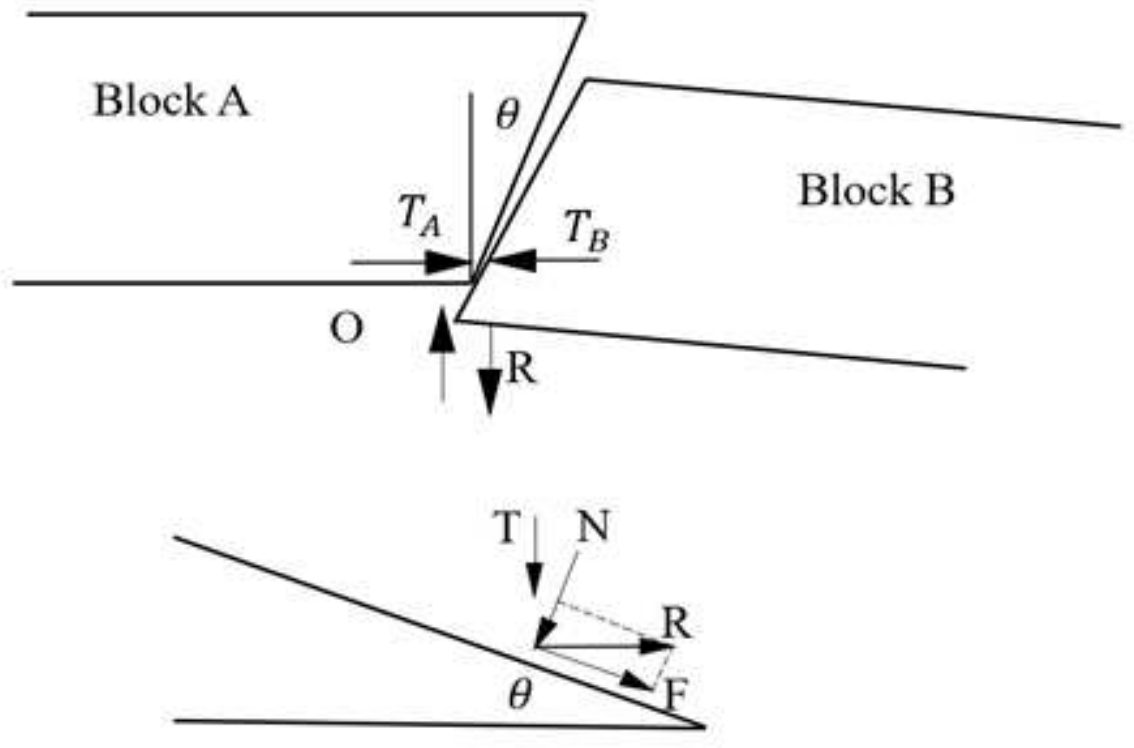

Figure 10

The balance of the rock block joint 


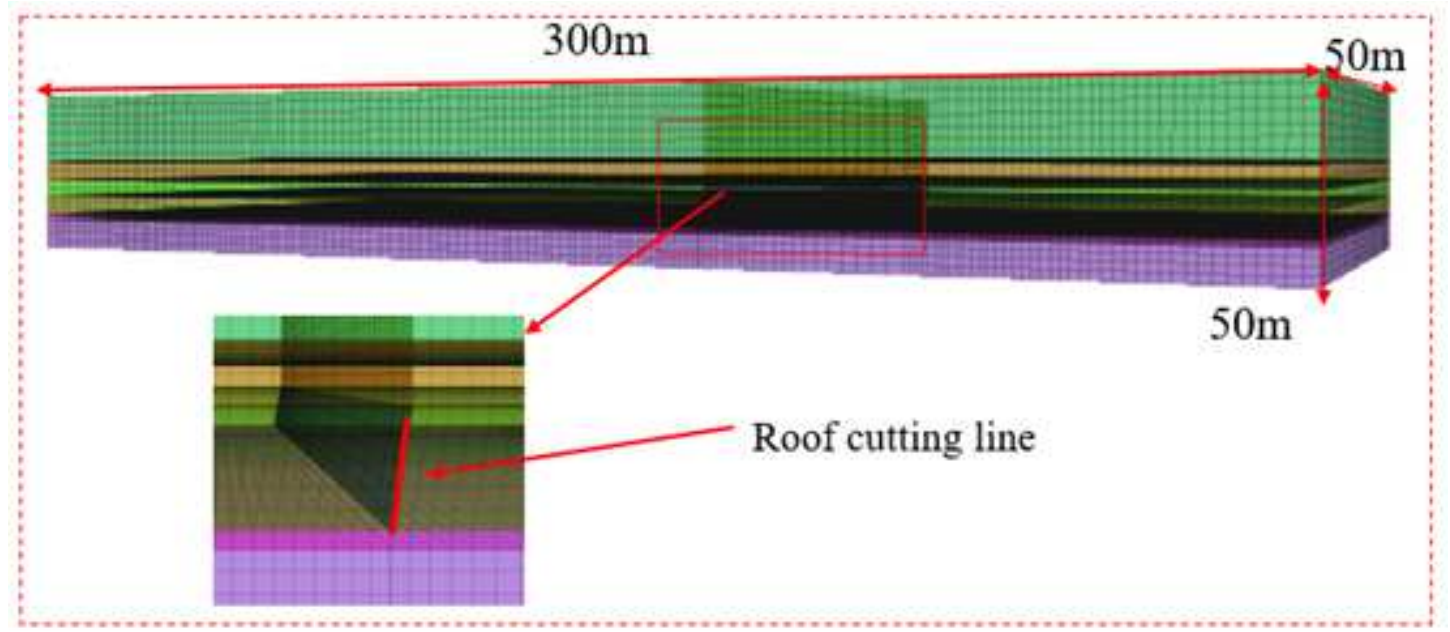

Figure 11

Numerical calculation model 


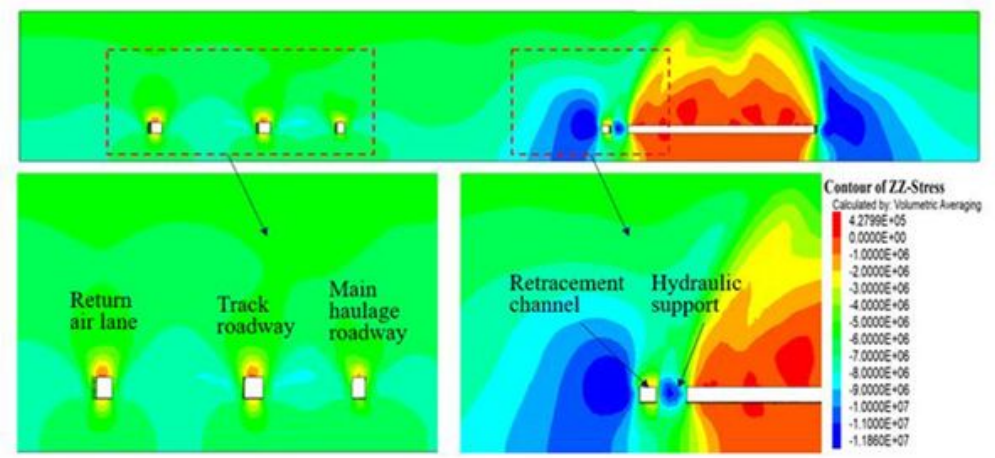

(a) No roof cutting and no evacuation of hydraulic support

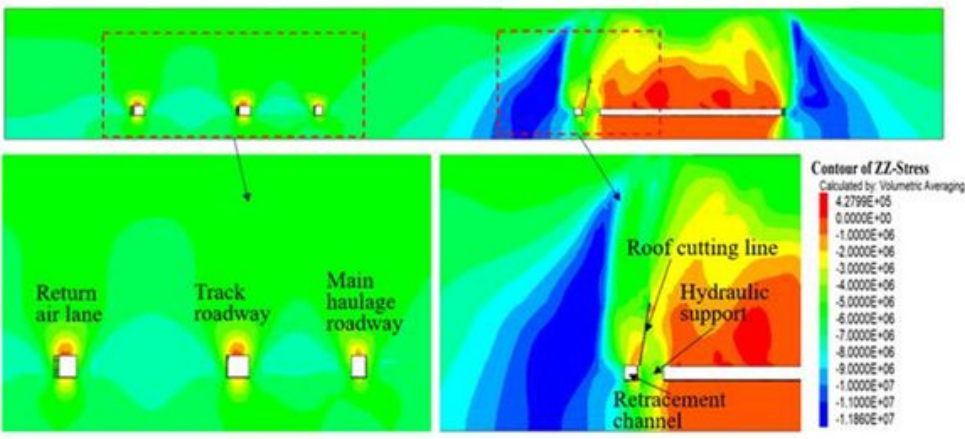

(b) Roof cutting and no evacuation of hydraulic support
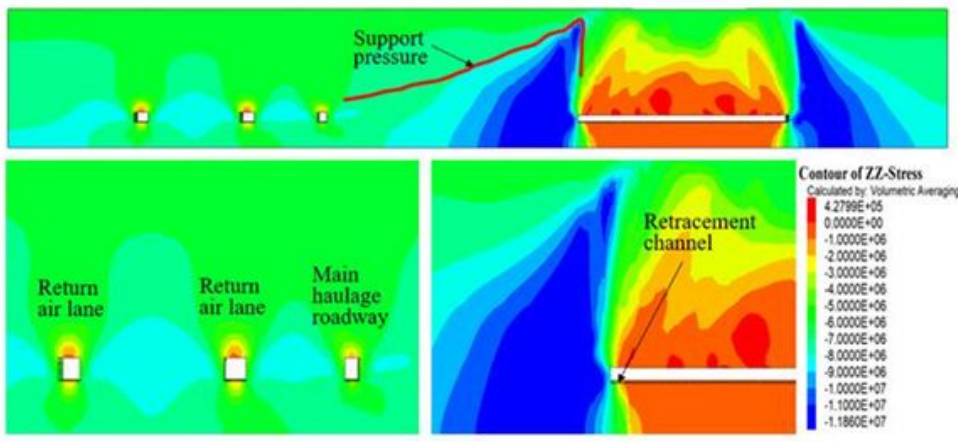

(c) No roof cutting and evacuation of hydraulic support
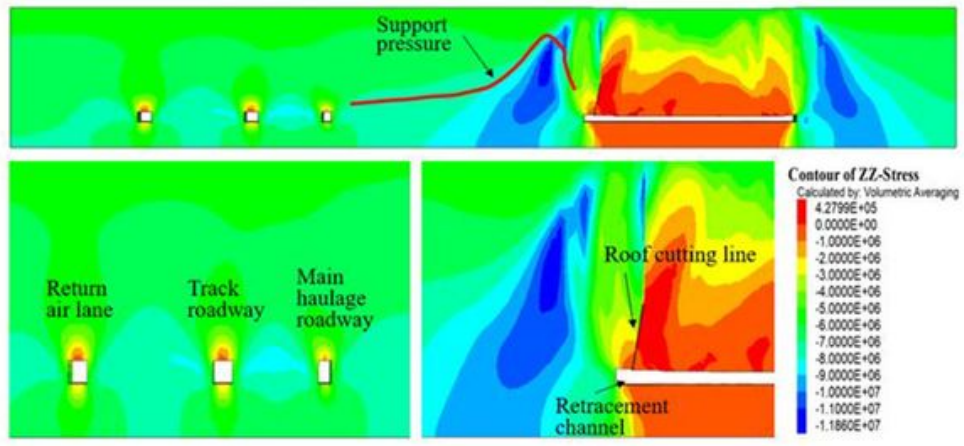

(d) Roof cutting and evacuation of hydraulic support

Figure 12

Numerical calculation results of vertical stress distributions. 


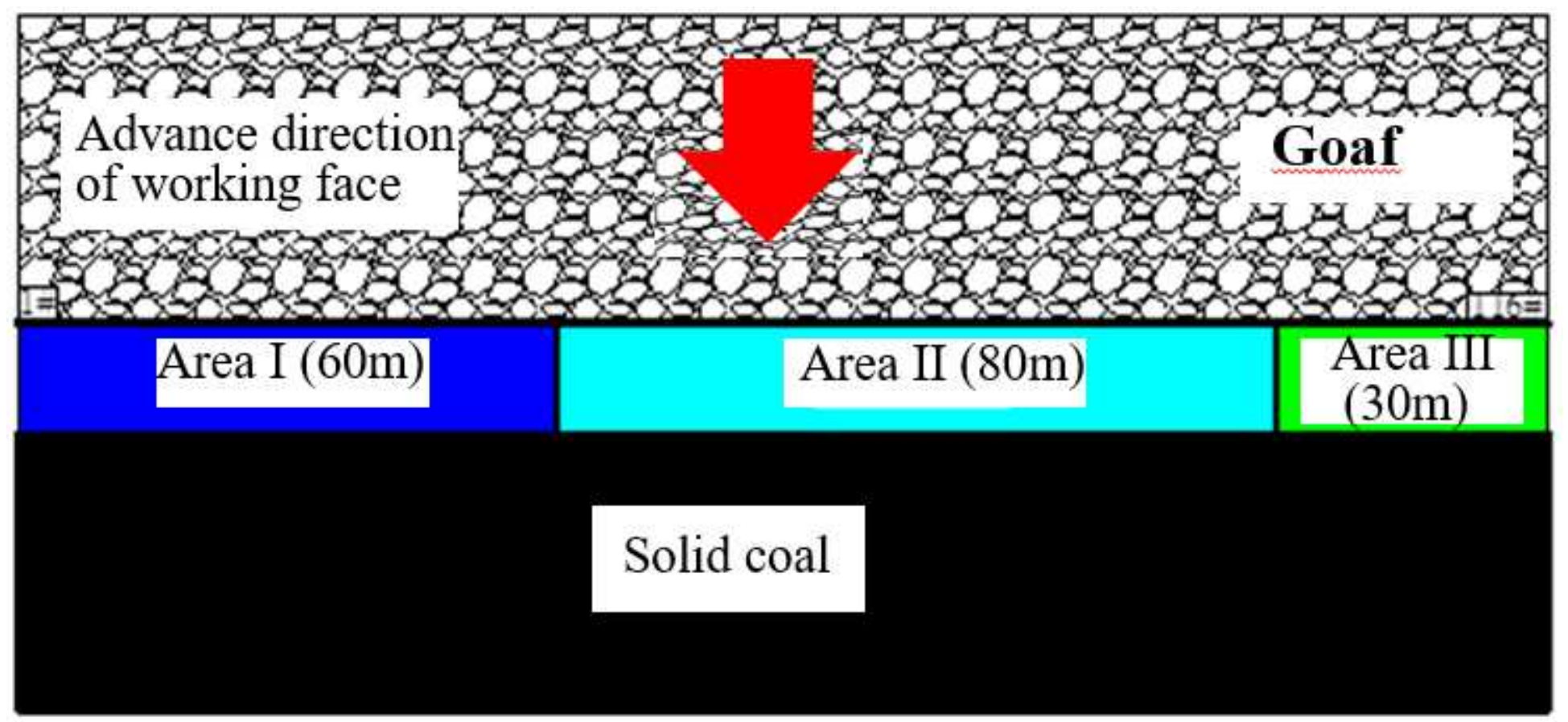

Figure 13

Schematic diagram of roof cutting partition

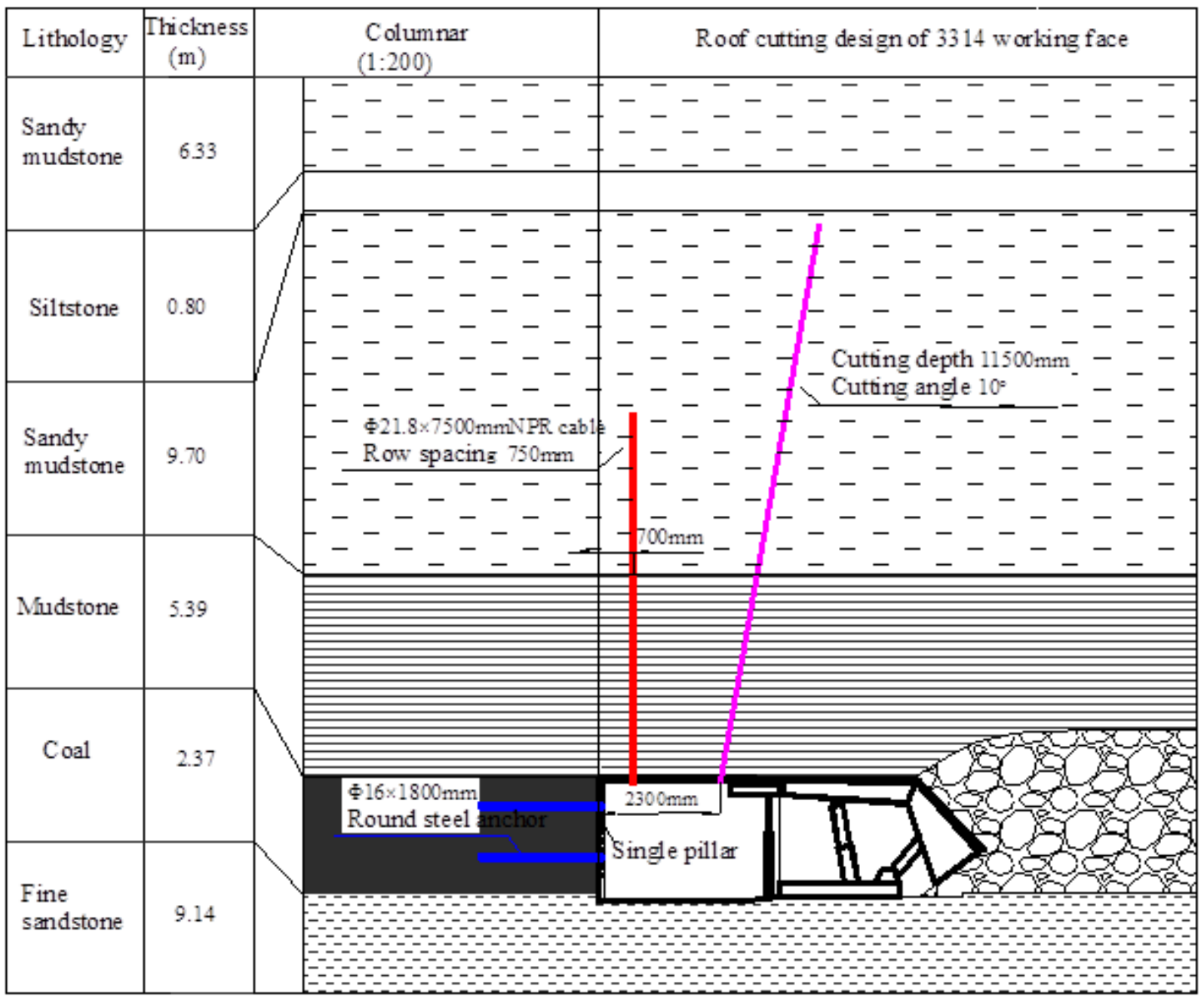


Figure 14

Roof cutting design of retracement channel
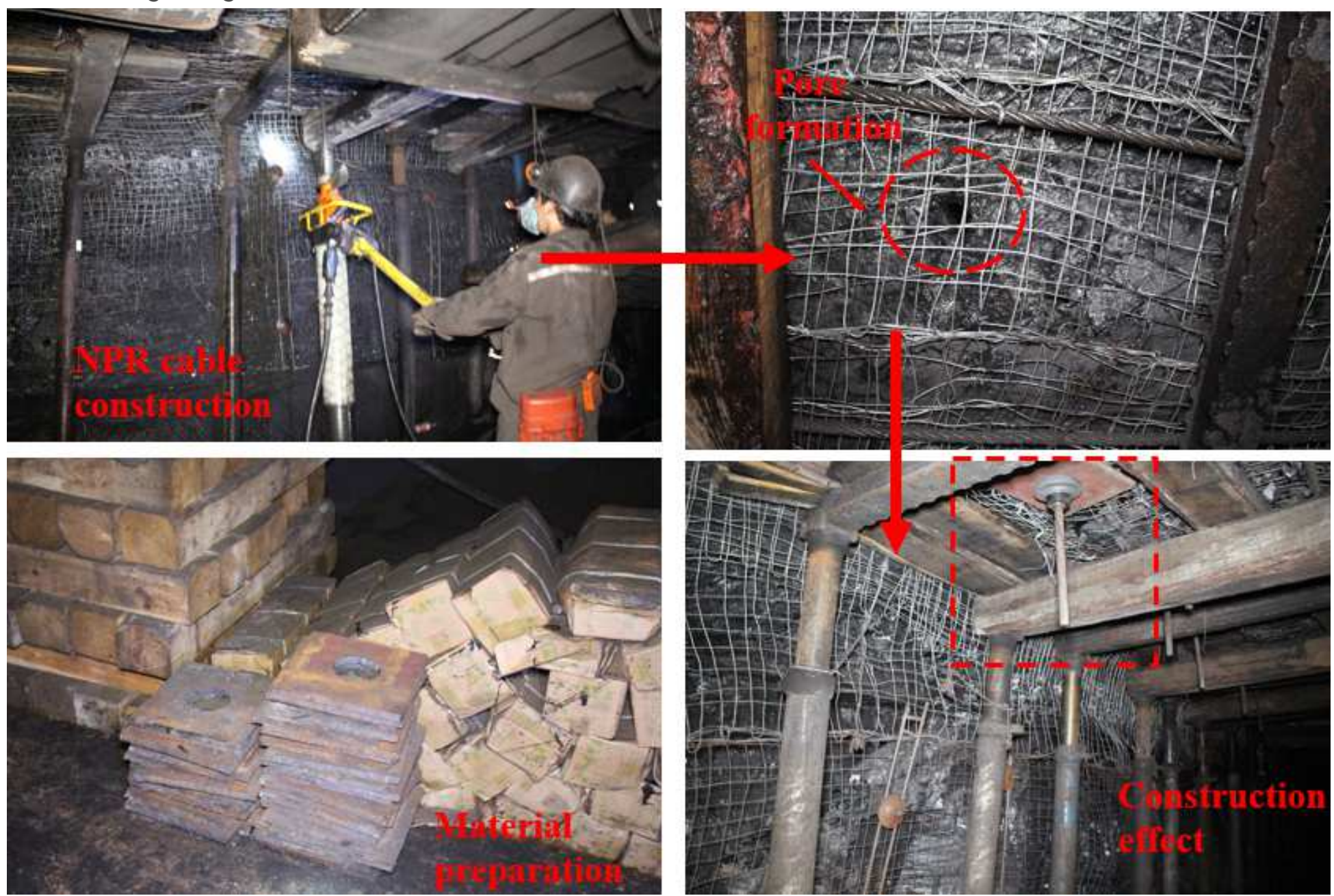

Figure 15

Construction of reinforcement support
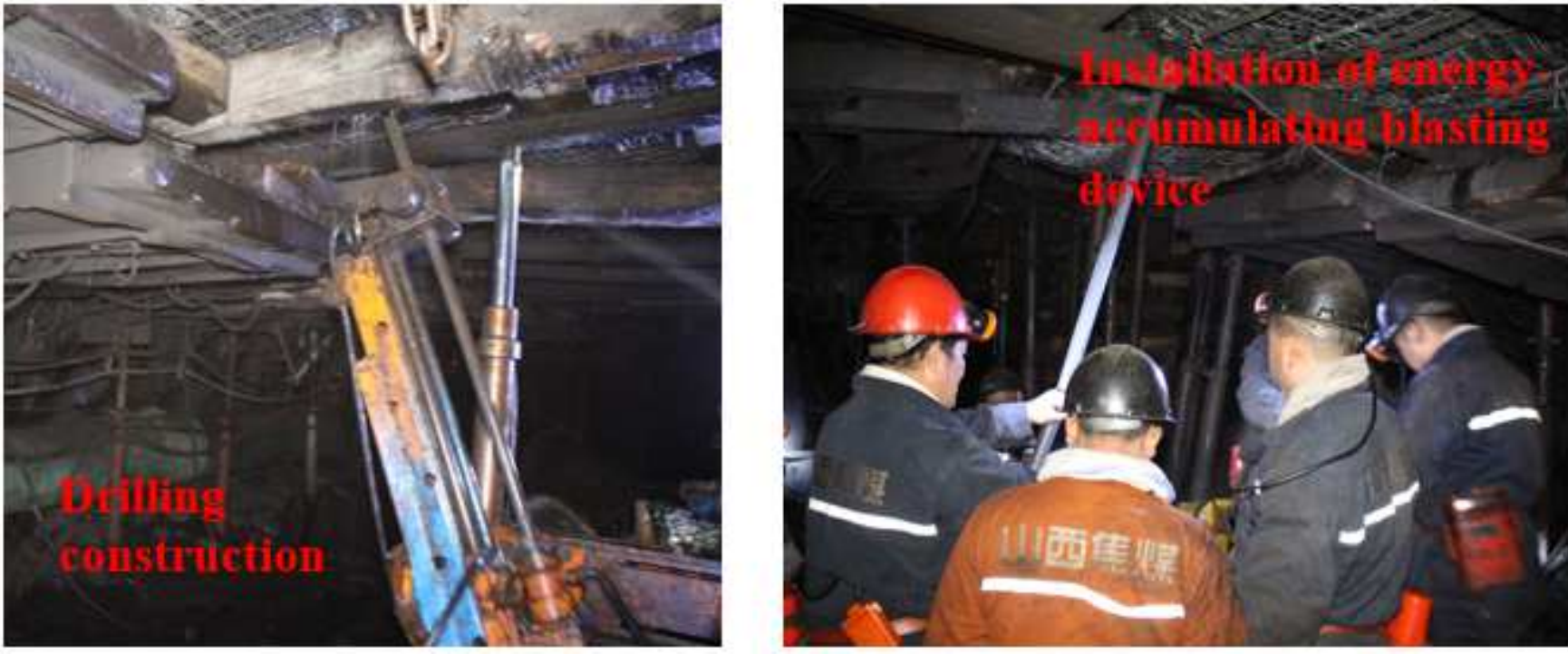
Figure 16

Cutting and charging construction 